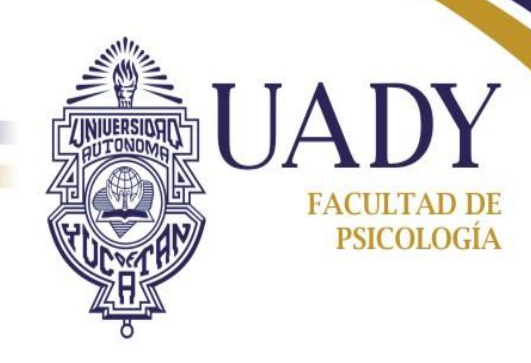

UNIVERSIDAD AUTONOMA DE YUCATAN

FACULTAD DE PSICOLOGÍA

PROTOCOLO PARA EL PRIMER TESTIMONIO EN NIÑOS Y ADOLESCENTES POR UN EQUIPO INTERDISCIPLINARIO.

QUE PARA OPTAR AL TÍTULO DE MAESTRO EN PSICOLOGÍA APLICADA EN EL ÁREA DE PSICOLOGÍA CRIMINOLÓGICA

\author{
PRESENTA
}

JOSÉ LUIS CHI ZALDÍVAR

ASESOR: MTRO. JOSÉ PAULINO DZIB AGUILAR

MÉRIDA, YUCATÁN, DICIEMBRE DE 2014 


\section{Protocolo para el Testimonio en Niños y Adolescentes}

\section{Dedicatoria}

La presente tesis la dedico a mi madre que siempre ha estado ahí para apoyarme.

A mi abuela que siempre ha creído en mí.

A mi novia Carolina por nunca dejar que me rindiera y darme ánimos en cada momento. 
Protocolo para el Testimonio en Niños y Adolescentes

\section{Reconocimientos}

Al Mtro. José Paulino Dzib Aguilar por su consejo y apoyo durante la realización de esta tesis, reconozco que sin él, esto no sería posible.

A la Mtra. Verónica Godoy Cervera por su interés y entusiasmo para asesorarme y guiarme en el área que tanto le apasiona, la Psicología del Testimonio.

Al Dr. Elías Coronado Góngora por su gran paciencia, sabiduría y consejo en las muchas ocasiones que me aconsejó para realizar esta tesis. 
Protocolo para el Testimonio en Niños y Adolescentes

Declaro que esta tesis es m ipropio trabajo a excepción de las citas en las que se ha dado crédito a los autores; asim ismo, que este trabajo no ha sido presentado previamente para la obtención de algún otro título profesionalo equivalente. 
Protocolo para el Testimonio en Niños y Adolescentes

Agradezco el apoyo brindado por el Consejo Nacional de Ciencia y Tecnología (CONACYT) por haberme otorgado la beca No. 337647 durante el periodo agosto 2012 - julio 2014 para la realización de mis estudios de maestría que concluyen con esta tesis, como producto final de la Maestría en Psicología Aplicada de la Universidad Autónoma de Yucatán. 


\section{CONTENIDO}

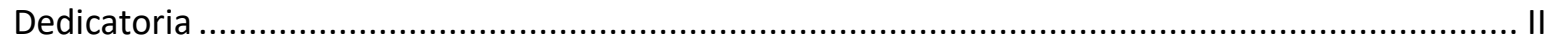

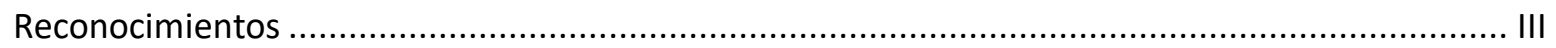

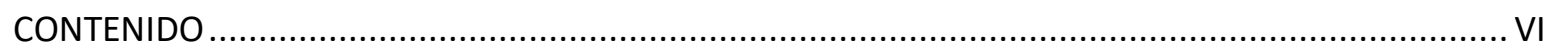

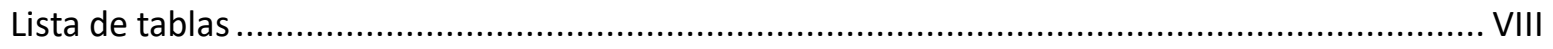

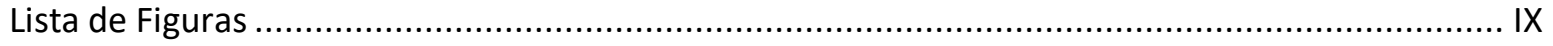

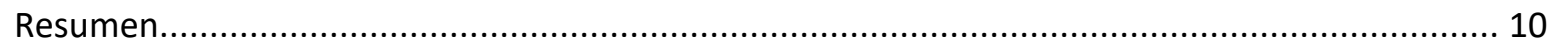

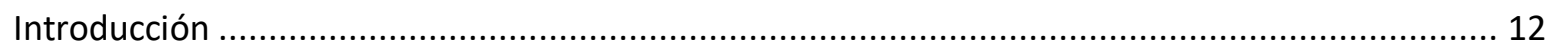

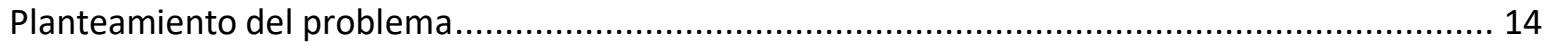

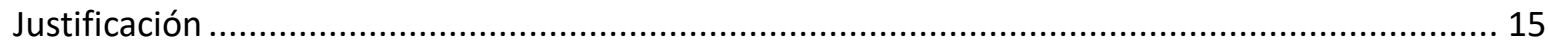

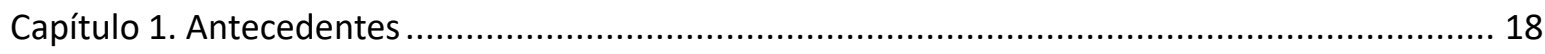

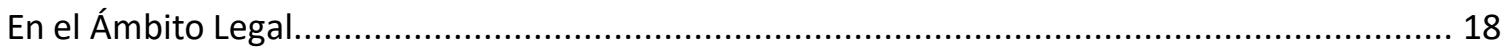

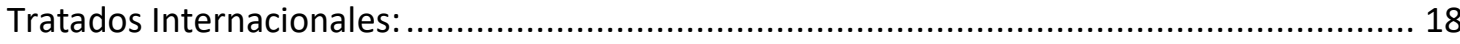

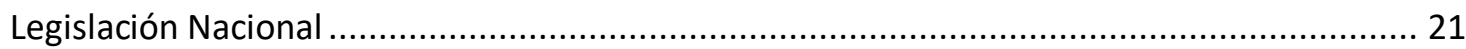

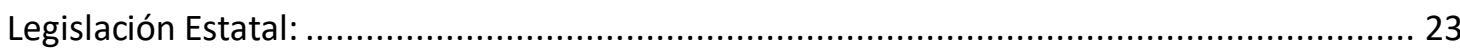

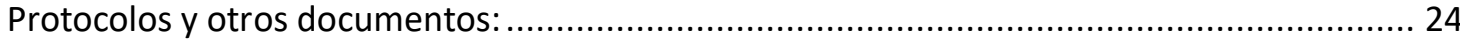

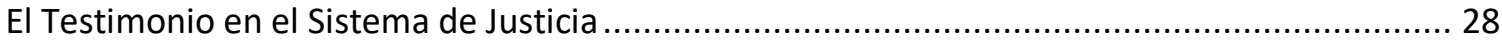

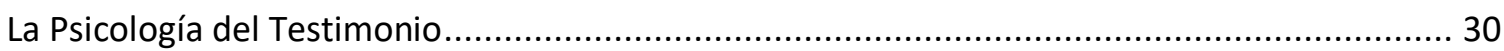

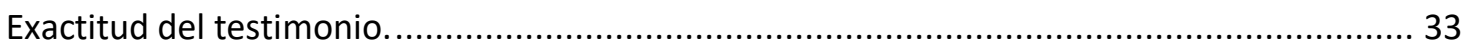

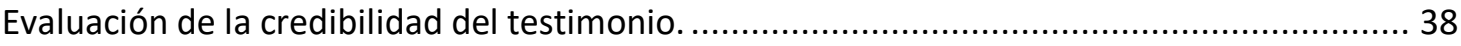

Técnicas e instrumentos para recuperar el testimonio ...................................................... 48

Protocolo de Entrevista Forense de Michigan: ......................................................... 49

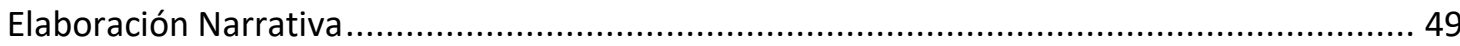

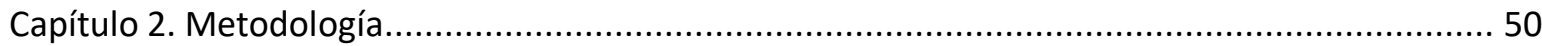

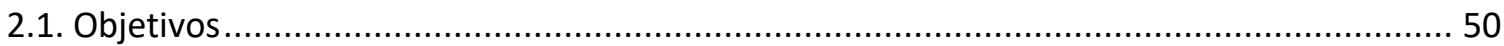

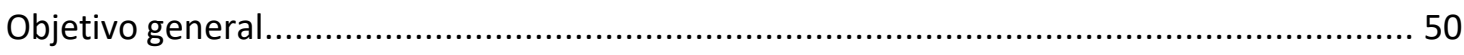

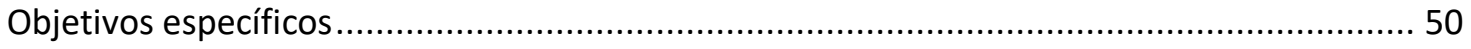

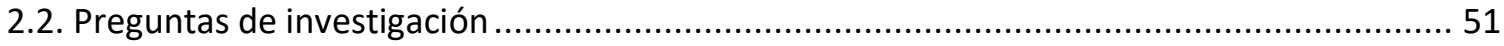

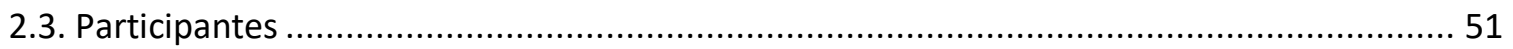

Fase cualitativa: revisión de documentos científicos, libros, artículos, leyes internacionales, nacionales y locales para construcción de las fases del protocolo. ...................................... 51

Fase cuantitativa (desarrollo y revisión del protocolo por parte de expertos): ...................... 51 


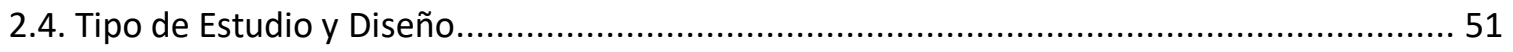

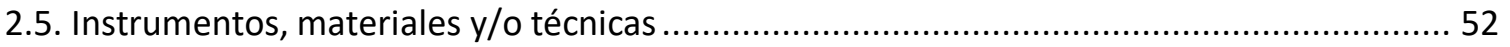

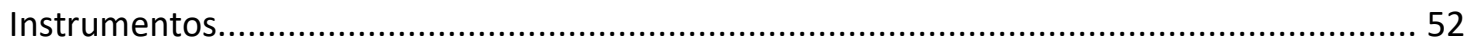

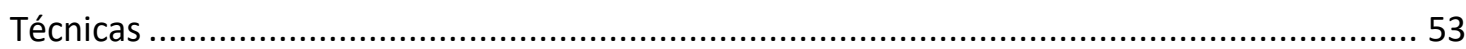

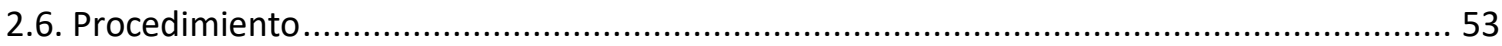

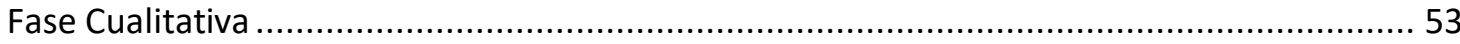

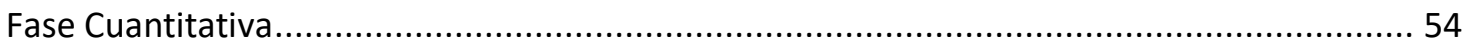

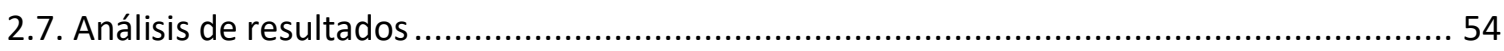

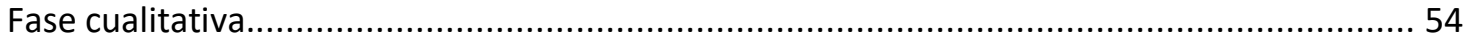

Fase cuantitativa.

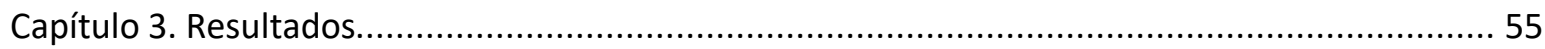

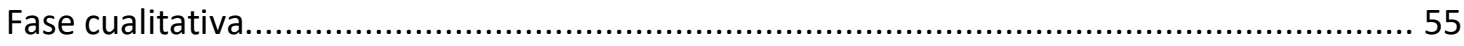

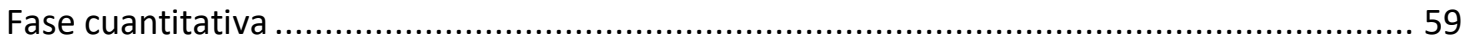

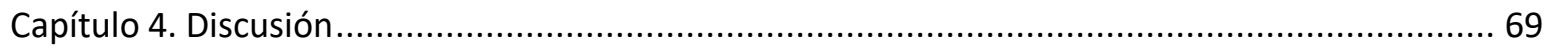

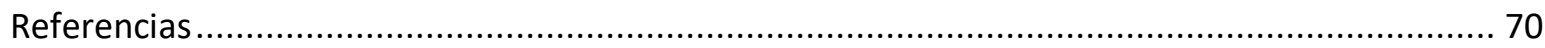

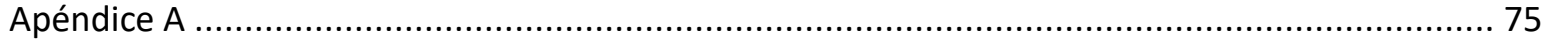

Protocolo para la toma del testimonio interdisciplinario en niñas, niños y adolescentes .............. 75

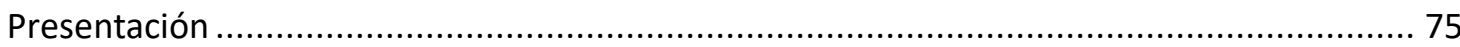

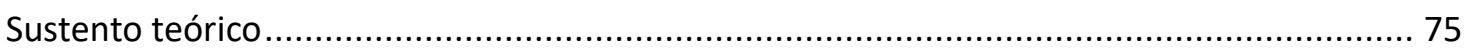

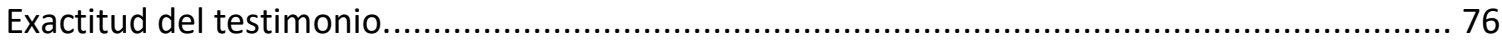

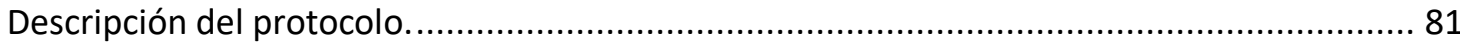

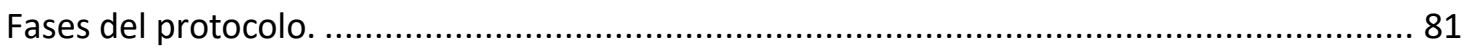

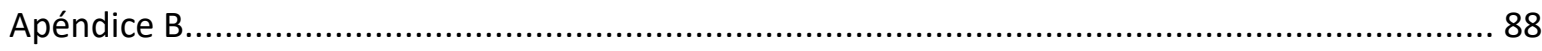

Cuestionario para evaluar el protocolo del testimonio ..................................................... 88 


\section{Lista de tablas}

Tabla 1: Información encontrada en la categoría "Legislación". 55

Tabla 2: Información relevante para la toma del testimonio de la categoría "Protocolos y Normas"

Tabla 3: Información relevante para la toma del testimonio de la categoría "Aportaciones de la Psicología". 58

Tabla 4: Medias aritméticas de las puntuaciones. 59 


\section{Lista de Figuras}

Figura 1: Frecuencia de las respuestas para la fase "Acreditación del delito"................... 61 Figura 2: Frecuencia de las respuestas para la fase "Preparación del menor y de los padres".

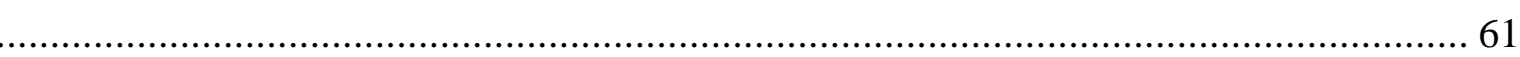

Figura 3: Frecuencia de las respuestas para la fase "Adecuación del espacio físico". ........ 62

Figura 4: Frecuencia de las respuestas para la fase "Preparación del equipo de video"..... 63

Figura 5: Frecuencia de las respuestas para la fase "Rapport"................................. 63

Figura 6: Frecuencia de las respuestas para la fase "Establecimiento de reglas".............. 64

Figura 7: Frecuencia de las respuestas para fase "Verdad/mentira". .............................. 64

Figura 8: Frecuencia de las respuestas para la fase "Práctica y memoria". ..................... 65

Figura 9: Frecuencia de las respuestas para la fase "Narrativa Libre".......................... 65

Figura 10: Frecuencia de las respuestas para la fase "Clarificación de dudas"................. 66

Figura 11: Frecuencia de las respuestas para la fase "Reformulación de preguntas"......... 66

Figura 12: Frecuencia de las respuestas para la fase "Cierre"...................................... 67

Figura 13: Frecuencia de las respuestas para la pregunta "Las fases sirven para cumplir con

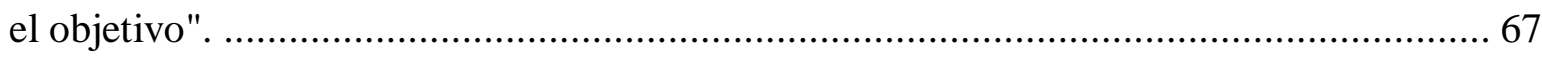




\section{Resumen}

La presente tesis tuvo como objetivo desarrollar un protocolo para la recuperación del primer testimonio de niños, niñas y adolescentes por un equipo interdisciplinario en el sistema penal oral y acusatorio.

La primera etapa de la creación del protocolo consistió en la revisión de las distintas legislaciones, normas, reglamentos, ya sean internacionales, federales o locales que validan y sustentan los procedimientos de la toma de testimonio en menores de edad, al igual que los documentos que protegen los derechos de las niñas, niños y adolescentes. También se revisaron investigaciones científicas referentes a la psicología del testimonio las cuales fungieron como base empírica para desarrollar las fases del protocolo.

Después de la revisión documental el protocolo fue sometido a evaluación por funcionario públicos adscritos al Tribunal Superior de Justicia del Estado de Yucatán, entre los participantes se encontraban jueces, técnicos judiciales, mediadores, psicólogas y trabajadoras sociales; la evaluación del protocolo consistió en que lo participantes calificaran que la pertinencia de las fases del protocolo para cumplir el objetivo del mismo, que es crear un protocolo interdisciplinario para sistematizar la toma del testimonio haciendo más eficiente el proceso al igual que evitar la sobre-victimización en menores de edad.

Los resultado de la evaluación fueron muy positivos de las trece fases propuestas para el protocolo, solo una fase obtuvo una puntuación baja (3.94), comparadas con la media de puntuación de las demás fases, las cuales eran mayores a 4.00. Sin embargo en la evaluación global del protocolo la calificación media fue de 3.94, siendo 5.00 la máxima puntuación posible, lo cual indica que a consideración de los participantes el protocolo puede ser mejorado para cumplir con su propósito.

Por último tomando en cuenta los resultados de la evaluación se realizaron las correcciones pertinentes al protocolo, entre estas correcciones ser modificó la fase de Rapport, describiendo con mayor precisión las actividades a realizarse y considerando que esta actividad forma parte de todo el proceso del protocolo y no como una fase aislada. 
Protocolo para el Testimonio en Niños y Adolescentes 


\section{Introducción}

En el año 2008 se da en México un cambio en el sistema de procuración de justicia, el cual busca que el sistema de procuración de justicia en México pase de ser un sistema de justicia inquisitivo en el que la contradicción y la publicidad del proceso están limitados a ser un sistema donde exista el principio de contradicción y publicidad (Contreras López, 2010).

Con este cambio del sistema penal se da cumplimiento a lo dispuesto en el Artículo Segundo Transitorio de la Reforma Constitucional Federal en materia de Seguridad y Justicia, publicado en el Diario Oficial de la Federación en fecha 18 de junio de 2008, entrando en vigor el 19 de junio de ese mismo año, el cual obliga a las Legislaturas locales, para que en un plazo que no exceda de ocho años, adopten el sistema penal acusatorio y adecuen toda su legislación interna a lo previsto en los artículos 16, párrafos segundo y decimotercero; 17, párrafos tercero, cuarto y sexto; 19; 20 y 21, párrafo séptimo de la Constitución Política de los Estados Unidos Mexicanos (H. Congreso del Estado de Yucatán, 2011).

El artículo 20 de la Constitución Política de los Estados Unidos Mexicanos señala que: "El proceso penal será acusatorio y oral. Se regirá por los principios de publicidad, contradicción, concentración, continuidad e inmediación. Posteriormente se señalan en el mismo artículo los principios generales del proceso, las garantías del inculpado y los derechos de la víctima. Estos puntos se desarrollaran con mayor atención más adelante.

Esta reforma busca que el sistema de justicia sea más ágil y eficiente. El sistema acusatorio tiene como finalidad mejorar en tiempo y calidad los procesos judiciales, incorporando mecanismos de transparencia e imparcialidad en el desarrollo de los mismos, usando mecanismos como: medios alternativos de solución de conflictos, principio de oportunidad, solución anticipada, juicio oral, jueces de garantías o de control, jueces de juicio oral y jueces de ejecución de sentencias (Contreras López, 2010). 
Como su nombre lo dice, el nuevo sistema penal tendrá una mayor preocupación por la oralidad, por lo tanto el testimonio será uno de los pilares probatorios dentro de este nuevo sistema, esto significa que el testimonio, tanto de víctimas como de inculpados será de vital importancia para la resolución de los casos penales.

En los diferentes ámbitos del ejercicio profesional del psicólogo, el disimulo, el encubrimiento, la exageración, el filtrado y el falseo de la información suministrada o la negación de problemas son fenómenos muy frecuentes y constituyen un importante obstáculo a la hora de realizar una correcta evaluación de cada caso y de tomar decisiones legales (Lemos, 2005). En el ámbito de la psicología jurídica o forense, el disimulo, encubrimiento, exageración, filtrado o falseo tienen repercusiones de gran peso, por ejemplo, el dicho de una persona puede conllevar a la encarcelación de un inocente.

La labor del psicólogo en el sistema de justicia, cobra un papel fundamental, pues la psicología del testimonio ha contribuido con información científica y válida que puede ayudar al proceso de justicia a recoger un testimonio de manera eficiente, valorar la exactitud de dicho testimonio y por último evaluar la credibilidad del mismo. 


\section{Planteamiento del problema}

Como se mencionó con anterioridad en este nuevo sistema procesal los testimonios serán uno de los elementos de prueba e investigación más importantes, en ocasiones, serán los únicos de los que se dispongan (Secretaría de Seguridad Pública, 2005). Así una declaración o una identificación pueden convertirse en los únicos argumentos para probar unos hechos a partir de los cuales dictar una sentencia (Manzanero, 2008).

Cuando se trata de niños, la mayoría de los casos que los implican como víctimas suelen ser privados, es decir, al momento del hecho sólo estaban presentes la víctima y el agresor, y no existe la posibilidad de incorporar información por parte de testigos (Secretaría de Seguridad Pública, 2005).

La relevancia del testimonio infantil en los asuntos que le competen, involucra la garantía de una serie de condiciones que busquen evitar sufrimientos a los niños y de que éste se recoja de manera óptima (Suprema Corte de Justicia de la Nación, 2014), debido a que los menores son una población vulnerable, pues presentan un mayor riesgo de sufrir una victimización secundaria o revictimización provocada por el sistema judicial, cuentan con una escasa capacidad para defender sus derechos sin ayuda y corren el riesgo de ser excluidas por el sistema (Gonzales, Muñoz, Sotoca, \& Manzanero, 2013).

Pero siempre se debe tener en cuenta que los procedimientos judiciales fueron diseñados por adultos y pensados para adultos. Si reconocemos que los niños son personas diferentes a los adultos, por lo tanto, dichos procesos deben ajustarse a las características de los menores, pues las características específicas de la infancia impactan de manera significativa la forma que rinde su testimonio (Suprema Corte de Justicia de la Nación, 2014). El niño posee características y necesidades particulares, diferentes a las de un adulto. Por lo que es necesario que al tomar la declaración de un niño, la persona que lo realice tenga conocimiento de estas características y se adapte a las necesidades del niño, primero para no sobre-victimizarlo durante el proceso y segundo para lograr obtener información adecuada y suficiente para el proceso judicial (Secretaría de Seguridad Pública, 2005). 
En otros lugares del mundo ya se han hecho avances en este aspecto, por ejemplo, en España, Manzanero y González (2013) diseñaron un procedimiento de análisis de credibilidad el cual contempla los procedimientos de valoración de las declaraciones (SRA, SVA, RM) y pautas para la valoración de la prueba de identificación del agresor y de la evaluación de la competencia para testificar; este procedimiento se conoce como el Enfoque Holístico para la Evaluación de la Prueba Testifical (HELPT). Aunque en México existen propuestas de protocolos para recuperar el testimonio, dichos protocolos se enfocan a cumplir con las normas jurídicas y no toman en cuenta las aportaciones realizadas por distintas áreas de la psicología, como la psicología del testimonio, que pueden aportar conocimientos válidos y científicos que apoyen los procesos para recuperar el testimonio. Por lo tanto en la presente tesis se propondrá un protocolo para recuperar el testimonio de un menor por un equipo interdisciplinario, el cual contemple en su estructura, usar de manera sistemática los principios jurídicos y científicos pertinentes.

\section{Justificación}

La principal aportación que busca la creación de un protocolo para recuperar el testimonio es desarrollar un proceso valido, confiable y sustentado por hallazgos científicos que de la certeza a las autoridades que el testimonio fue recuperado de manera confiable, y que es el adecuado para tomarlo en consideración como un elemento probatorio dentro del proceso de justicia.

La creación de dicho protocolo se sustenta en el artículo 249 primer párrafo, del Código Procesal Penal para el Estado de Yucatán, el cual señala que: “Cuando deban realizarse diferentes peritajes a personas agredidas sexualmente, incapaces o menores de edad, deberá integrarse, en un plazo breve, un equipo interdisciplinario, con el fin de concentrar en un misma sesión las entrevistas que requiera la víctima"; el segundo párrafo de dicho artículo también menciona que: "Antes de la entrevista, el equipo de profesionales deberá elaborar un protocolo y designará, cuando lo estime conveniente, a uno de sus miembros para que se encargue de plantear las preguntas". También está sustentado por las Directrices sobre la Justicia en Niños Víctimas y Testigos de Delitos que en su apartado 
de aplicación señala que los profesionales que trabajen con niños víctimas y testigos de delitos deberán hacer todo lo posible para adoptar un enfoque interdisciplinario y cooperativo para ayudar a los niños; dicho enfoque puede incluir protocolos para las distintas etapas del proceso de justicia.

La creación de un Protocolo para la Toma del Testimonio brindaría a los psicólogos que se desempeñan en el área de la psicología jurídica, psicología forense y psicología del testimonio, así como a otros profesionistas (abogados, policías investigadores, criminalistas, criminólogos, etc.) una herramienta útil para poder recuperar el testimonio disminuyendo al mínimo los sesgos y errores por parte de los profesionistas involucrados.

Otro beneficio de la creación del protocolo sería agilizar y optimizar el proceso de evaluación de la exactitud y credibilidad de testimonio a la que son sujetos personas, que en muchas ocasiones, fueron víctimas de un delito y están pasando por un proceso de crisis emocional, conflictos y muchas dificultades. Este beneficio ayudaría a prevenir la sobre-victimización de los individuos, que se encuentran en un proceso legal.

Aunque existen en el mundo distintos protocolos orientados a obtener el testimonio de los individuos como el Protocolo de Entrevista Forense de Michigan, E.U. o el Sistema de Evaluación Global creado en España por Ramón Arce, estos protocolos están hechos de acuerdo a las necesidades específicas de los sistemas de justicia y las leyes de los países donde fueron creados.

En México existen modelos o protocolos para la toma de testimonio buscando que este proceso se adecue a las características específicas del nuevo sistema de justicia acusatorio y oral, que se está implementando en todo el territorio mexicano, y las características de desarrollo del menor, por ejemplo el Protocolo de actuación para quienes imparten justicia en casos que involucren niñas, niños y adolescentes, Protocolo Iberoamericano de actuación judicial para mejorar el acceso a la justicia de personas con discapacidad, migrantes, niñas, niños adolescentes, comunidades y pueblos indígenas y el Modelo especializado para la toma de 
Protocolo para el Testimonio en Niños y Adolescentes

declaraciones infantiles. Sin embargo carecen de sistematización y de validación, además que estos no especifican como deben realizarse los procesos y mucho menos toman en cuenta los hallazgos científicos que la psicología del testimonio ha encontrado. 


\section{Capítulo 1. Antecedentes}

\section{En el Ámbito Legal}

Debido a que el proceso de recuperación o toma de testimonio se da dentro de un proceso de justicia penal, es importante que la presente tesis esté sustentada jurídicamente con base en los tratados internacionales, leyes federales y estatales que están en vigor en el momento de la realización del presente trabajo.

Tratados Internacionales: son todos los documentos promulgados por organismos internacionales, como la Organización de las Naciones Unidas que han sido ratificados por México.

Convención sobre los Derechos del Niño: Esta convención, fue publicada en 1989, sin embargo es el principal documento internacional que protege los derechos fundamentales de cualquier menor en el mundo; en los países que hayan ratificado dicho documento. A grandes rasgos esta declaración presenta cuatro principios que protegen al menor, los cuales son:

- Principio de interés superior del niño: el cual implica que en cualquier decisión judicial o del Estado se tiene que velar por el bienestar e intereses del menor, aun cuando se trate de situaciones que no lo involucren directamente.

- No discriminación: tal principio sostiene que "todo niño, niña o adolescente es titular de los derechos humanos que le son reconocidos sin distinción alguna por motivos de raza, color, sexo, idioma, religión, opinión política o de otra índole, origen nacional, étnico o social, posición económica, impedimentos físicos, nacimiento o cualquier otra condición del niño, de sus padres o de sus representantes legales”. Sin embargo este principio va más allá de lo señalado anteriormente, pues de acuerdo a la Suprema Corte de Justicia de la Nación (2014) ya que la infancia presenta características particulares en relación a su desarrollo cognitivo, emocional y moral que le impiden ejercer ciertos derechos, como el de acceso de justicia, es necesario que se realicen adecuaciones procesales que permitan la participación plena de niños, niñas y adolescentes; así también señala que las y los juzgadores deben tomar las 
previsiones necesarias para que las distintas etapas procesales (medidas de protección, toma de declaración y periciales) se desarrollen de acuerdo con las características y necesidades de niños, niñas y adolescentes.

- Principio de derecho a la vida, supervivencia y desarrollo: este principio alienta a que en cualquier decisión judicial deberá evaluarse su impacto en la vida (entendida desde el enfoque de condiciones dignas de existencia), la supervivencia y el desarrollo del niño.

Convención Americana sobre los Derechos Humanos: Señala en su artículo noveno que: "Todo niño tiene derecho a las medidas de protección que en su condición de menor requieren por parte de la familia, de la sociedad y del Estado”.

Directrices sobre la Justicia en Asuntos Concernientes a Niños Víctimas y Testigos de Delitos: Este documento realizado por el Consejo Económico y Social de las Naciones Unidas establece las prácticas adecuadas basadas en el consenso respecto a los conocimientos contemporáneos y las reglas, normas y principios regionales e internacionales pertinentes. Estas directrices señalan que los profesionales deben cuidar que se respeten los principios de dignidad, no discriminación, interés superior del niño, protección, desarrollo armonioso y derecho a la participación.

De igual manera dichas directrices señalan los derechos que todos los niños, niñas y adolescentes los cuales son:

- Derecho a un trato digno y respetuoso: incluye que las entrevistas, exámenes y demás tipos de investigación sean realizados por profesionales capacitados con el fin de evitar el sufrimiento de los niños.

- Derecho a la protección contra la discriminación: esto incluye que los proceso de justicia y servicios de apoyo tomen en cuenta las características de los niños víctimas y testigos y de sus familias, como edad, deseos, nivel educativo, sexo, 
orientación sexual, culturales, religiosas entre otras. Igualmente todo niño deberá ser tratado como una víctima capaz, a reserva de su examen, y su testimonio no se considerará carente de validez o de credibilidad solo en razón de su edad.

- Derecho a ser informado: los niños y sus familias deben de ser informados en todo momento de sus derechos, la situación del proceso, la fase del proceso en el que se encuentran, etc.

- Derecho a ser oído y a expresar opiniones y preocupaciones.

- Derecho a una asistencia eficaz. Lo cual incluye que los profesionales deben adoptar y aplicar medidas para que a los niños les resulta más fácil prestar testimonio o declarar, especialistas y los familiares apropiados pueden acompañar al niño mientras rinde testimonio.

- Derecho a la intimidad.

- Derecho a ser protegido de sufrimientos durante el proceso de justicia: este derecho incluye el uso de salas de entrevista concebidas para los niños y recesos durante el testimonio de un menor. También se menciona limitar el número de entrevistas, se deben aplicar procedimientos especiales para obtener pruebas de los niños víctimas y testigos de los delitos a fin de reducir el número de entrevistas, declaraciones y concretamente todo contacto innecesario con el proceso de justicia. Otro punto a considerar es que los niños deben ser interrogados de forma adaptada a ellos, facilitar el testimonio del niño y reducir la posibilidad de que este sea objeto de intimidación, por ejemplo, nombrando expertos en psicología.

- Derecho a la seguridad.

- Derecho a la reparación.

- Derecho a medidas preventivas especiales. 
Declaración de los Derechos del Niño: dicha declaración que fue proclamada por la Asamblea General de las Naciones Unidas a fin de que el niño, niña o adolescente puedan tener una infancia feliz y gozar, en su propio bien y en bien de la sociedad. A continuación se señalaran aquellos principios que estén relacionados con la toma del testimonio.

El segundo principio de la Declaración, señala que los niños deben gozar de protección especial y disponer de oportunidades y servicios, dispensado todo lo anterior por la ley y otros medios, con el fin de que se desarrolle física, mental, moral, espiritual y socialmente en forma saludable y normal. Por lo tanto se espera que se deban tomar en cuenta medidas especiales para que el menor pueda rendir su testimonio.

Y también es importante señalar el principio ocho, el cual menciona que el niño debe, en todas circunstancias, figurar entre los primeros que reciban protección y socorro; por lo tanto en el sistema de justicia, el niño, niña o adolescente debe recibir protección de manera prioritaria.

Legislación Nacional: se refiere a todas las leyes y códigos vigentes en el territorio mexicano.

Ley para la Protección de los Derechos de las Niñas, Niños y Adolescentes: en su artículo $3^{\circ}$ menciona que: "la protección de los derechos de las niñas, niños y adolescentes, tiene como objetivo, asegurarles un desarrollo pleno, integral, lo que implica la oportunidad de formarse física, mental, emocional, social y moralmente en condiciones de igualdad”. El mismo artículo señala que los principios rectores de los derechos de niñas, niños y adolescentes son:

- El del interés superior de la infancia.

- El de la no-discriminación. 
- El de igualdad sin distinción de raza, edad, sexo, religión, idioma o lengua, opinión política o de cualquier otra índole, origen étnico, nacional o social, posición económica, discapacidad, circunstancias de nacimiento o cualquiera otra condición suya o de sus ascendientes, tutores o representantes legales.

- El de tener una vida libre de violencia.

- El de corresponsabilidad de los miembros de la familia, Estado y sociedad.

- El de la tutela plena e igualitaria de los derechos humanos y de las garantías constitucionales.

En el titulo segundo, de los derechos de niñas, niños y adolescentes; capitulo primero, del derecho a la prioridad; artículo 14, “Niñas, niños y adolescentes tienen derecho a que se les asegure prioridad en el ejercicio de todos sus derechos..." por lo que se debe velar primero por cumplir los derechos de los niños antes de cualquier otra persona.

Código Nacional de Procedimientos Penales: el cual en su artículo 109, inciso XXVI señala que al tratarse de menores de edad se debe resguardar la identidad, por lo que cualquier proceso debe ser realizado cuidando que no se conozca la identidad del menor, el mismo artículo en su párrafo segundo indica también que... "en el caso de que las víctimas sean personas menores de dieciocho años, el Órgano jurisdiccional o el Ministerio Público tendrán en cuenta los principios de interés superior de los niños o adolescentes, la prevalencia de sus derechos, su protección integral..." por dicha razón se esperaría que los órganos gubernamentales tomen las medidas pertinentes para asegurar la no sobre-victimización del menor, lo cual ocurre cuando el menor víctimas de un delito, es sometido a procedimientos que vulneran su estabilidad emocional y psicológica, como lo puede ser la toma múltiple de un testimonio.

El artículo 275 del mismo código que habla de los peritajes especiales señala que: "cuando deban realizarse diferentes peritajes a personas agredidas sexualmente o cuando la naturaleza del hecho delictivo lo amerite; deberá integrarse un equipo interdisciplinario 
con profesionales capacitados en atención a víctimas, con el fin de concentrar en una misma sesión las entrevistas que ésta requiera, para la elaboración del dictamen respectivo".

Legislación Estatal: Son todos los reglamentos, códigos o leyes que están en vigor en el momento de la realización del presente trabajo y cuya aplicación corresponde al territorio del estado de Yucatán.

Código Procesal Penal para el Estado de Yucatán: dentro del presente código es importante señalar el art. 87 que indica que: “será deber de los fiscales investigadores durante todo el proceso adoptar medidas o solicitarlas, en su caso, para proteger a los testigos y víctimas de los delitos; facilitar su intervención en el mismo y evitar o disminuir cualquier perturbación que hubieren de soportar con ocasión de los trámites en que deben intervenir", por lo tanto es una obligación de los agentes del ministerio proteger al menor que testifica cuidando que esta intervención no perturbe su salud mental o emocional.

Un punto importante es que según el artículo 97 del mismo código: "La policía no podrá recibir declaración del imputado. En caso de que el imputado manifieste su deseo a declarar, se deberá comunicar ese hecho al fiscal para que tome las medidas necesarias para que declare inmediatamente...", por lo tanto en caso de menores de 18 años pero mayores de 12 años, la toma del testimonio o declaración deberá realizarse ante un agente de la fiscalía.

En cuanto a las víctimas del delito el artículo 100, inciso VI, sobre los derechos de las víctimas señala que la víctima debe: “....recibir del Estado asesoría jurídica, atención médica, psicológica y protección especial de su integridad física psíquica... cuando reciba amenazas o corra peligro en razón del papel que cumple en el proceso penal" por lo que el menor que participe en un proceso de testimonio debe ser protegido en todo momentos por el Estado. 
El artículo 249 señala que: "Cuando deban realizarse diferentes peritajes a... menores de edad, deberá integrarse un equipo interdisciplinario con el fin de concentrar en una misma sesión las entrevistas que requiera la víctima. ... el equipo de profesionales deberá elaborar un protocolo y designará, cuando lo estime conveniente, a uno de sus miembros para que se encargue de plantear las preguntas".

Protocolos y otros documentos: Existen en la actualidad otros protocolos que buscan establecer lineamientos y procedimientos de cómo deben actuar los participantes del sistema de justicia, jueces, abogados, psicólogos, policías, agentes ministeriales, etc. ante menores que estén inmersos en un proceso legal. A continuación se mencionaran los principales protocolos de distintos lugares del mundo y que con frecuencia son usados en México por los profesionales en psicología forense o disciplinas afines.

\section{Protocolo Iberoamericano de Actuación Judicial para Mejorar el Acceso a la Justicia de Personas con Discapacidad,} Migrantes, Niñas, Niños, Adolescentes, Comunidades y Pueblos Indígena: Como su nombre lo indica este protocolo está dirigido a diferentes grupos en situación de vulnerabilidad, pero se describirá lo relacionado a la actuación del menor dentro del proceso de justicia.

Este protocolo enlista las siguientes reglas y consideraciones que los juzgadores deben tomar en cuenta cuando una niña, niño o adolescente se encuentre dentro de un proceso de justicia, en cuanto a la toma de testimonio dicho protocolo establece las siguientes recomendaciones:

- Medidas para facilitar el testimonio: las y los jueces deberán adoptar y aplicar las medidas pertinentes para que a niñas, niños y adolescentes les resulta más fácil participar en el proceso, tal como permitir que personal especializado o los padres acompañen a los menores cuando den su testimonio. 
- Idioma e intérprete: el proceso de la toma de testimonio debe realizarse en un idioma sencillo y comprensible para niñas, niños y adolescentes.

- Preparación del niño para participar sin temor: previo al proceso a realizarse se debe explicar al menor en un lenguaje claro y sencillo en que constará el proceso.

- Testificación: es importante que ningún niño será obligado a testificar contra su voluntad o sin el conocimiento de sus padres o tutores, con excepción de que estos sean los probables autores del delito cometido contra el niño o si la patria potestad o custodia es cuestionada.

- Exhorto a decir verdad: el juez, magistrado y personal especializado de apoyo deben asegurarse que el niño entienda y manifieste a su modo que se conduce o conducirá con la verdad.

- Presencia de personal capacitado: se procurará que en toda declaración, ampliación o plática sostenida con el niño se cuente con la presencia de personal capacitado en la atención especializada a niños.

- Requerimientos metodológicos: independientemente de la metodología usada para intervenir con el niño se debe cuidar que esté basada en las características de desarrollo del niño, debe permitir la narrativa libre por parte del niño, debe contemplar la adecuada elaboración de preguntas para el esclarecimiento del hecho, contemplar el uso de adecuado de materiales de apoyo para la expresión del niño y contemplar estrategias para el manejo de la tensión y estrés del niño, así como la detección y manejo de mecanismos de defensa psicológicos.

- Registro de la participación del niño: toda actuación infantil deberá ser grabada en audio e imagen en su totalidad.

- Valoración del dicho infantil: dicha valoración se realizará tomando en cuenta sus derechos y su grado de desarrollo, deberá hacerse considerando los criterios de credibilidad y las condiciones en las que fue tomada dicha declaración y su posible afectación sobre la actuación del niño. 
Protocolo de Entrevista Forense de Cornerhouse (RATAC): Este protocolo fue creado por CornerHouse, una interagencia para la evaluación del abuso de los niños y centro de entranamiento en 1989 y desde entonces ha sido replicado en más de 17 estados de la unión americana. Este protocolo toma en consideración aspectos como la etapa de desarrollo del menor, en el engloban aspectos como la memoria, el periodo de atención, comprensión, el entendimiento de conceptos complejos, pensamiento concreto versus abstracto, el tipo de preguntas específicas que deben hacerse acorde a la edad del menor de edad, los procesos de inferencia de los menores de edad, también incorpora instrucciones para discernir entre verdad y mentira.

De acuerdo a Anderson, Ellefson, Lasley, Lukas, Olinger, Russell, Stauffer y Weigman (2009), los apartados que maneja este protocolo son:
a) Rapport,
b) Establecer la mejora manera de comunicación del menor de edad,
c) Establecer la competencia del menor de edad para declarar,
d) Evaluación breve del desarrollo del menor de edad,
e) Establecer el uso de modelos anatómicos,
f) Precauciones para no sugestionar,
g) Introducción al tema de la entrevista,
h) Temas sobre abuso,
i) Temas sobre cuestiones sexuales,
j) Preguntas específicas y
k) Conclusión. 
Protocolo de Entrevista Forense de Michigan: Como su nombre lo señala este protocolo fue creado en el estado de Michigan en Estados Unidos, es el resultado de un proyecto fundado por la Governor's Task Force para el Abuso y Negligencia Infantil, hasta la fecha se han realizado tres versiones de este protocolo, el primero publicado en 1996 (Governor's Task Force on Child Abuse en Neglect and Deparment of Human Services, 2011).

Este protocolo establece entre las diferentes etapas para la recuperación del testimonio las siguientes:

a) Preparación de la entrevista,

a. Recuperar información del hecho,

b. Genera hipótesis alternativas y

c. Preparar el ambiente de la entrevista.

b) Presentación y rapport,

c) Establecer reglas,

d) Realizar una entrevista de práctica,

e) Introducir el tema de la entrevista,

f) Facilitar la narrativa libre,

g) Preguntas y clarificaciones y

h) Cierre de la entrevista.

Este protocolo brinda recomendaciones sobre el espacio físico, el número de personas que deben participar en la entrevista, también recomienda que el proceso de entrevista sea grabado en audio y video, las adecuaciones del lugar de entrevista, y consejos que 
el entrevistador debe tomar en cuenta, como la edad del menor y la etapa de desarrollo en la que se encuentra o los cuidados que hay que tener para ciertos tipo de delitos (como el abuso sexual).

\section{El Testimonio en el Sistema de Justicia}

El testimonio es un acto fundamental en nuestro derecho procesal y se refiere a las declaraciones hechas sobre los hechos y las identificaciones de los autores, las cuales buscan obtener una descripción de lo ocurrido y las personas participantes, así como su reconocimiento, por lo que están influidas por los procesos atencionales, perceptivos, de memoria, lenguaje y pensamiento (Gonzales, Muñoz, Sotoca, \& Manzanero, 2013).

El testimonio en sí ha sido estudiado durante muchos años por la Psicología del Testimonio, que consiste en el conjunto de conocimientos basados en resultados de investigación de los campos de la Psicología Experimental y Social, que intentan determinar la calidad (exactitud y credibilidad) de los testimonios, que sobre los delitos, accidentes o sucesos cotidianos, prestan los testigos presenciales (Colegio Oficial de Psicólogos, s.f.).

La prueba testifical en sus diferentes expresiones (descripciones e identificaciones) es uno de los pilares probatorios en los distintos procesos judiciales, resultando de especial importancia en los procesos penales como señala el juez de control en los procesos de capacitación a académicos y personal judicial, en la instalación del sistema oral y acusatorio (Mugarte, 2014).

Las entrevistas a las víctimas o testigos tienen varios objetivos específicos, que según Gudjonsson (1992) (como se citó en Ibañes Peinado, 2008) son:

a) descubrir si se ha cometido un delito y, si es así, qué tipo de delito;

b) encontrar evidencias para identificar a los responsables; 
c) conseguir evidencias para evitar al delincuente culpable utilizar una defensa inapropiada; y

d) determinar si los testigos están diciendo la verdad

Los tópicos sobre los que ha versado mayoritariamente la investigación dentro de la Psicología del Testimonio han sido cuatro (Manzanero, 2008).

a) Los factores de influencia en la exactitud de los testimonios, ya que los testimonios pueden ser imprecisos atendiendo a distintos factores que pueden incidir en el proceso de codificación, almacenamiento y recuperación del recuerdo.

b) Los procedimientos de obtención de declaraciones que permitan obtener la mayor cantidad posible de información exacta, sin influencias negativas.

c) La evaluación de la credibilidad del testimonio, ya que constituye una demanda histórica por parte del Derecho a la Psicología la elaboración de métodos de detección de testimonios falsos (por engaño o error).

d) Las pruebas de identificación realizadas por testigos y la evaluación de su exactitud, que ayudarían a evitar, o al menos minimizar, algunos de los errores que se cometen y a valorar adecuadamente la actuación de los testigos.

La Suprema Corte de Justicia de la Nación (2014) en su Protocolo Iberoamericano de Actuación Judicial para Mejorar el Acceso a la Justicia de Personas con Discapacidad, Migrantes, Niñas, Niños, Adolescentes, Comunidades y Pueblos Indígenas señala que dentro del aspecto legal, para la participación de una persona en un proceso judicial, concretamente al dar su testimonio, se requiere de habilidades concretas como los son:

- Capacidad para comprender el lenguaje hablado.

- Capacidad para elaborar un relato de manera coherente y ordenada. 
- Capacidad para recordar los hechos de manera precisa y suficiente.

- Capacidad de controlar la angustia para sobrellevar una situación angustiante.

- Capacidad de mantener la atención y concentración durante la diligencia, aún bajo altos niveles de estrés.

Es importante mencionar que el testimonio, como indicio dentro de un proceso de investigación judicial, posee ciertas características que lo convierten en un elemento a considerar con cuidado, por ejemplo, de acuerdo a Gonzales et al. (2013) éste se deteriora con el paso del tiempo, se reconstruye cada vez que el testigo (víctima o imputado) recuerda y narra los hechos, con la posibilidad de que se contamine con información del entorno, las preguntas formuladas, los medios de comunicación o los comentarios de otros. Dicha degradación o deterioro es más grave cuando se trata de testigos vulnerables, como los menores de edad, cuanto más tiempo haya pasado y en sucesos mediáticos (Gonzales et al., 2013).

Así, considerando el testimonio como un indicio, debería seguir los mismos cuidados que cualquier otro indicio en una investigación judicial, por lo tanto los testimonio deberían seguir una cadena de custodia; ya que cuando no se guarda la cadena de custodia de un indicio, éste deja tener de validez, ante la posibilidad de contaminación, sustitución, alteración o destrucción. Los recuerdos pueden sufrir estos efectos cuando no se actúa con las debidas precauciones y en ese sentido la prueba testifical podría igualemente quedar invalidada (Gonzalez et al., 2013).

\section{La Psicología del Testimonio}

El estudio del testimonio es una temática que ha sido estudiada durante mucho tiempo por diferentes autores, lo que llevó a que se desarrolle el área de la psicología conocida como Psicología del Testimonio o del Testigo. Para Saíz, Baqués y Saíz (2005) (como se 
citó en Espinosa, 2011) la Psicología del Testimonio es una subespecialidad de la psicología jurídica y que denota su campo de aplicación dentro de la psicología forense.

Ya en 1982, Hosch y Cooper (Ibañez Peinado, 2008) mencionaban que el principio común que guía la investigación en el campo de la psicología del testimonio es el convencimiento de que el testimonio de las víctimas y/o de los testigos que sufren o presencian un determinado hecho, el cual es delictivo, es la base fundamental, y a veces única, de las investigaciones de esclarecimiento de los delitos.

Aun al día de hoy existe una gran controversia sobre el nombre, origen y pertenencia de la psicología del testimonio o del testigo; en España se le conoce como psicología del testigo y algunos autores la consideran parte de la psicología forense aplicada la cual tiene como objeto investigar y aportar datos científicos sobre la fiabilidad y credibilidad de los testigos (Pozo Huerta, 2006).

La investigación en la psicología del testimonio comenzó en los últimos años del siglo XIX y comienzos del siglo XX, sus primeros orígenes se basan en el trabajo de Alfred Binet sobre la sugestionabilidad de la memoria de los niños y otros autores franceses como Claperède y Duprée con trabajos que estudiaron la psicología del testigo (Espinosa, 2011). Por otra parte la obra de Münsterberg “On The Witness Stand” determinó el origen de la psicología del testimonio, en la que señala la necesidad de una reforma legal basada en la experimentación científica, ya que el testimonio de un testigo, aun actuando de buena fe, puede ser erróneo (Ibabe Erostarbe, 2000). También es importante el trabajo del psicólogo americano Whipple en sus diferentes artículos publicados denota el interés en el estudio de los testigos y sus reportes (Espinosa, 2011).

Así podría definirse a la Psicología del Testimonio como la subespecialidad de la psicología jurídica que denota su campo de aplicación dentro de la psicología forense, que tiene como objeto de estudio el testimonio y los factores que median su exactitud, teniendo en consideración la forma como los procesos superiores, en especial la memoria, la percepción y la atención influyen en el 
mismo; de igual manera se nutre constantemente de la investigación científica que le ha aportado diferentes herramientas de validación de los testimonios y detección del engaño (Ibabe, 2000 y Espinosa, 2011).

Desde sus inicios, la psicología del testimonio se ha dirigido hacia la investigación experimental, muchas de estas investigaciones se han centrado en las variables que pueden influir en la memoria del testigo, específicamente en las fases de codificación y recuperación del recuerdo, por nombrar algunas se encuentra la investigación de Tulving y Thompson (1973) sobre como la manera en que se codifica la información tiene una gran influencia en la recuperación posterior de dicha información; Craik y Watkins, también en 1973 estudiaron la relación entre el número de ensayos de un ítem y el recuerdo del mismo.

En tiempos modernos la investigación en Psicología del Testimonio tiene dos claras aplicaciones profesionales: por un lado, para el psicólogo criminalista (aplicaciones de técnicas de entrevista para el interrogatorio policial, elaboración de retratos robots o reconocimiento de sospechosos) y por otro, para el psicólogo forense (facilitar la toma de declaraciones de las partes y asesorar a los tribunales para un mejor valoración del prueba testifical) (Muñoz, et al., 2011). Y por otro lado la psicología del testimonio se ha centrado en dos claros vectores de estudios: una es la exactitud y la otra, la credibilidad. (Saíz Roca, Baques Cardona y Saíz Roca, 2006).

El estudio de la exactitud o validez se preocupa del análisis de los factores que pueden incidir sobre la fidelidad o exactitud entre lo que realmente ocurrió y lo que el testigo relata. En esta aproximación se supone que el testigo es honesto, pero que su memoria puede fallar, por lo que se analiza la exactitud e inexactitud del testigo. Por otra parte el estudio de la credibilidad analiza la continuidad entre la verdad y la falsedad del testimonio, incluye los testimonios de testigos honestos que por razones independientes de su voluntad faltan a la verdad de su recuerdo, así como las versiones falsas de un testigo que tiene la intención de mentir (Pozo Huerta, 2005). 
Exactitud del testimonio. Este elemento del testimonio está fuertemente relacionado con la exactitud de la memoria, la cual se entiende como la reproducción de forma correcta y compleja de los hechos originales. Existen ciertas circunstancias que pueden afectar la memoria de las personas volviéndola imprecisa o inexacta. Wells hizo una de las primeras clasificaciones de las variables que afectan la exactitud de la memoria: variables a estimar de las circunstancias en las que se producen los sucesos y variables propias del sistema para tomar declaración a los testigos (Pozo Huerta, 2005).

Las variables a estimar se pueden dividir en dos categorías, primero los factores de la situación, los cuales son aspectos como las condiciones ambientales en las que se produjo el suceso (distancia, oscuridad, niebla), el tipo de suceso (violación, accidente, robo, etc.) la duración del suceso, grado de violencia del mismo, etc.La segunda categoría, factores de los testigos, alude a las características de cada testigo, como el sexo, edad, estrés, expectativas, perjuicios, valores y entrenamiento. En cambio las variables del sistema se refieren a aquellos aspectos que pueden ser manipulados y optimizados o, al contrario, influir negativamente en el recuerdo de los hechos o la identificación del sospechoso. Entre estas variables se encuentran las instrucciones dadas a los testigos, el intervalo de tiempo entre la denuncia y la declaración, el tipo de preguntas y el orden en que se formulan, la composición de las ruedas de identificación, la información post-suceso que el sujeto pueda recibir por parte de algún funcionario de la policía (Pozo Huerta, 2005).

Manzanero (2010) categoriza estas variables de acuerdo a los factores que afectan la huella de la memoria, así están divididas en:

a) Factores que afectan la fase de codificación de la memoria, b) factores que afectan la fase de retención de la información y c) factores que afectan la recuperación de la información.

A continuación se presentan las principales variables a estimar y del sistema que pueden afectar el testimonio de las personas. 


\section{Variables a estimar.}

Condiciones de iluminación. Los cambios bruscos en las condiciones de iluminación pueden causar un pobre sensibilidad visual. Los testigos presenciales que han sido sometidos a cambios bruscos en las condiciones de iluminación durante el suceso pueden tener dificultades para percibir adecuadamente los hechos (Pozo Huerta, 2005).

Duración del suceso. El tiempo de exposición al suceso es un factor importante para un mejor rendimiento de la memoria, a mayor duración del suceso, éste podrá ser mejor percibido y codificado (Pozo Huerta, 2005)

Violencia del suceso. Algunos estudios sugieren que la violencia de un suceso puede dificultar la capacidad de un sujeto para percibirlo y recordarlo. Otros estudios aseveran que la violencia de un suceso puede distorsionar las percepciones ocurridas desde el inicio de la violencia. Los hechos emotivos parecen provocar el efecto de que la gente se preocupe por sí misma, se inquiete y se distraiga más. Easterbook a finales de los cincuenta destacó los efectos de las emociones en la selectividad de la atención, señalando que un suceso altamente emotivo está acompañado de una disminución de la atención, debido a lo cual tienden a percibirse menos detalles, a pesar de que el tema principal de suceso y los detalles importantes pueden ser percibidos y recordados (Pozo Huerta, 2005)

Estrés y miedo. La ley de Yerkes-Dodson sugiere que el nivel de rendimiento aumentará a veces y disminuirá en otras ocasiones por los aumentos de estrés. De acuerdo a esta ley existe un nivel óptimo de estrés en el que el rendimiento de un sujeto es mejor. En el ámbito forense existen opiniones divididas sobre los efectos del estrés en el testimonio. Deffenbacher (1983) revisó un total de 21 investigaciones sobre el estrés y la memoria del testigo, 11 de estos estudios sugieren que niveles de estrés altos disminuyen la precisión del testigo, los otros 10 señalan que la activación alta no disminuye la precisión del recuerdo. Deffenbacher argumentó que los primeros estudios trataron con niveles de activación más parecidos a los que ocurren en homicidios, asaltos, robos y violaciones (Pozo Huerta, 2005). 
Focalización en el arma. Un efecto del estrés consiste en que se reduce la atención, de tal forma que las personas se concentran en ciertas características de su entorno y, consecuentemente, prestan menos atención a otras características. Este fenómeno de focalización en el arma alude a la concentración de la atención del testigo en un arma y a la resultante reducción en la habilidad para recordar otros detalles del crimen (Pozo Huerta, 2005).

Estrés crónico. Alude a un estado de ansiedad causada por ciertos sucesos vitales estresantes. El estrés crónico puede causar preocupación de modo que los individuos no prestan atención a los estímulos de su entorno, pudiendo perder información import ante y necesaria para un recuerdo preciso (Pozo Huerta, 2005).

Expectativas y estereotipos. La memoria de los testigos está influenciada por los conocimientos y experiencias adquiridas. Se ha comprobado que si un testigo no puede precisar algún tipo de información, recurre a los estereotipos. Los sujetos pueden recurrir a los estereotipos en situaciones donde la percepción del suceso ha sido imperfecta y sobre todo si, mientras declaran, son presionados para dar información (Pozo Huerta, 2005).

Edad. En general los niños ofrecen una información más limitada que los adultos, pero lo que dicen no es menos exacto. También se cree que los niños más pequeños son más sugestionables, y aunque en varios estudios se ha visto que los niños menores de tres años son más sugestionables que los adultos, sin embargo en investigaciones con niños mayores de cinco años no se han encontrado diferencias en la sugestionabilidad de los niños y los adultos. En estudios con personas de la tercera edad algunos estudios concluyen que los testigos mayores no son tan capaces como los jóvenes adultos de describir o identificar a la gente que han visto antes. Por lo tanto hay que tratar el testimonio de las personas mayores con cautela, lo que no implica desvalorizar su testimonio (Pozo Huerta, 2005). 
Sexo: Con respecto a esta variable las investigaciones muestran que en general el sexo de los testigos no afecta a su memoria (Pozo Huerta, 2005).

Entrenamiento. Esta variable se refiere al grado en que una persona en virtud de su empleo, experiencia o entrenamiento, puede ser mejor testigo que otra. El entrenamiento puede aumentar la probabilidad de que un testigo haga un esfuerzo deliberado durante el proceso para prestar atención a los detalles y tratar de recordarlos. En una investigación realizada por Loftus en 1981 se comparó a detectives de delitos de incendios con estudiantes en cuanto a su habilidad para recordar detalles de una película que mostraba un incendio en un hospital (Pozo Huerta, 2005).

\section{Variables del sistema.}

Olvido. Son muy conocidas las investigaciones de Ebbinghaus sobre el olvido y como sus resultados dieron origen a la llamada "curva del olvido", la cual muestra que los sujetos olvidan una gran parte de la nueva información poco después de aprenderla y posteriormente el olvido se va haciendo más gradual. Aplicado al testimonio es obvio que en cuanto más tiempo pase entre el hecho presenciado y la primera declaración, más deterioro existirá en el recuerdo de los sucesos, pero no solo existe el riesgo de deterioro del recuerdo sino el de su distorsión o transformación (Pozo Huerta, 2005).

Información post-suceso. Durante la retención del evento, las experiencias posteriores al suceso pueden afectar a la memoria del suceso original, alternando o trasformando el recuerdo de este. Varias investigaciones han comprobado que las presuposiciones son capaces de transformar el recuerdo de una persona, así como también de complementarlo. Por lo tanto es posible introducir información falsa en el recuerdo de una persona y después la persona relata esa información como si realmente hubiese ocurrido (Pozo Huerta, 2005). 
Métodos de interrogación. Numerosas investigaciones dan cuenta que el tipo de preguntas realizadas en los interrogatorios a testigos pueden inducir el recuerdo de cosas que nunca han estado presentes (Loftus, Greene, \& Doyle, 1994). Para reconstruir el recuerdo del testigo de manera eficaz el entrevistador debe conocer las formas en que la evocación del recuerdo puede verse afectada por distintos métodos de elicitación. Los investigadores han sugerido que se obtendrían buenos resultados con una estrategia de interrogatorio que primero permita una narración libre para después hacer preguntas específicas, teniendo mucho cuidado con la forma en que se realiza la pregunta (evitar preguntas sugestivas o inductoras) (Pozo Huerta, 2005).

Recuperación múltiple. La cantidad de veces que un testigo ha tenido que recuperar un suceso, es uno de los factores importantes de distorsión que se deben de tener en cuenta al analizar la exactitud del recuerdo del testigo. Los individuos involucrados en un proceso penal suelen narrar varias veces lo que han presenciado; en el caso de abuso sexual a menores, estos pueden ser preguntados alrededor de unas 30 o 50 veces por aproximadamente nueve personas diferentes (padres, profesores, médicos, trabajadores sociales, abogados, jueces, policías, psicólogos, etc.) y no todos procuran hacer preguntas sin contaminar el recuerdo (Cantón \& Cortés, 2006).

Cada vez que se recuerda un suceso la huella mnémica que lo representa se reconstruye, lo que implica que con cada recuperación los recuerdos se van transformando mediante la incorporación de nuevos datos y la reinterpretación de los ya existentes (Cantón \& Cortés, 2006). Esto quiere decir que a mayor cantidad de declaraciones que la persona dé sobre el suceso habrá una mayor diferencia con respecto a la primera declaración hecha.

Tiempo trasncurrido desde el suceso. Manzanero y Diges (1994), encontraron que la preparación juega un papel determinante en la calidad del recuerdo, mientras más tiempo pase entre el suceso y la declaración la persona puede construir el recuerdo, lo que dificulta la capacidad de los evaluadores de determinar correctamente si un recuerdo es real o imaginario. 
Evaluación de la credibilidad del testimonio. La credibilidad se define como la valoración subjetiva de la exactitud estimada de las declaraciones de un testigo. Esta valoración se basa en inferencias que consideran diferentes aspectos como las circunstancias y características del delito, nuestros conocimientos y creencias, y la congruencia estimada entre las declaraciones y otros elementos de prueba (Manzanero y Diges, 1993 como se citó en Manzanero, 2008). La credibilidad hace referencia al grado de veracidad que se atribuye a la declaración de un testigo, es decir, si el testigo está engañando o no con su declaración (Sáiz Roca, Baqués Cardona, \& Sáiz Roca, 2006).

No se trata de determinar, si un testigo en su personalidad tiende a hacer declaraciones falsas, o quizás, si ya lo ha hecho; un mentiroso empedernido puede hacer, en un caso específico, declaraciones creíbles; la credibilidad trata de determinar, si los sucesos descritos en la declaración corresponden a hechos realmente vividos (Heinz, 2000). La preocupación radica fundamentalmente en si se cree que lo que dice el testigo es lo que ocurrió verdaderamente, lo cual puede deberse no solo a que la memoria del testigo falla sino también a la intención de mentir (Saíz Roca et. al., 2006).

Existe un gran número de técnicas e instrumentos para realizar una evaluación de credibilidad de testimonio, en este apartado se describirán las principales técnicas usadas para evaluar la credibilidad del testimonio. Estas técnicas se agrupan en tres categorías: a) Técnicas psicofisiológicas, b) Conductuales y c) Narrativas o de la declaración (Bembibre Serrano \& Higueras Cortés, 2010).

Instrumentos y técnicas del análisis de la conducta No-verbal. Se puede considerar a Paul Ekman como el padre de la detección de la mentira o engaño por medio del análisis de indicadores no verbales. Aunque en su teoría para la detección de la mentira Ekman menciona una serie de dificultades para detectar la mentira como por ejemplo la dificultad del evaluador para monitorear todos los aspectos de la conducta del posible mentiroso (el habla, expresiones faciales, movimientos de las manos, postura, gestos, etc.) o la 
diferencias individuales en los procesos corporales relacionados al engaño, también menciona que los individuos pueden ser entrenados para poder detectar la mentira a través de ciertas pistas de las emociones que pueden relacionarse con la mentira, por ejemplo: las pausas y errores en el discurso, aumento en el tono de la voz, alto volumen de la voz, palidez del rostro y pistas para detectar cuando una emoción es falsa como la asimetría en las expresiones faciales o que la emoción no debe mostrarse de manera abrupta (Howitt, 2009).

El supuesto de estas técnicas radica en que ciertas emociones son muy difíciles de controlar y, por tanto, son también difíciles de controlar las experiencias no verbales cuando se experimentan dichas emociones. La mentira es una conducta compleja que requiere de una alta demanda cognitiva; así, el sujeto que miente puede ser incapaz de dominar las conductas asociadas a ciertas emociones, pues toda su atención se encuentra centrada en elaborar un relato creíble (Saíz Roca et. al., 2006).

El estudio del engaño a través de indicadores conductuales se ha conceptualizado dentro de tres grandes líneas de investigación. La primera se centra en el estudio de la capacidad del emisor de mentir y la del receptor para detectar la mentira. La segunda atiende el efecto del acceso a diferentes canales de información (rostro, cuerpo, tono de voz, etc.) sobre la precisión al juzgar la credibilidad. La tercera línea de estudio se orienta a la identificación de las conductas concretas indicadoras de engaño (Godoy Cervera \& Dzib Aguilar, 2010).

Desde las década de 1970 se han realizado estudios para analizar el carácter predictivo de algunos de los indicadores sobre conducta no-verbal, los cuales se pueden clasificar en tres grandes categorías:

- Características vocales: dudas o pausas en el habla, errores al hablar, cambios en el tono de voz.

- Características faciales: miradas, sonrisas y parpadeo. 
- Movimientos: auto-manipulaciones, movimientos ilustradores del discurso, movimientos de manos, dedos, piernas, cabeza, tronco y cambios de la posesión personal.

Vrij (2000) realiza una revisión de estudios que analizan estos indicadores y menciona los siguientes comportamientos como posiblemente relacionados a la conducta del mentiroso.

- Tienden a utilizar un tono de voz más agudo, probablemente debido al estrés.

- Realizan mayores pausas durante la declaración, posiblemente porque el esfuerzo cognitivo es mayor.

- En algunos estudios se señala que cometen más errores al hablar, se muestran más dubitativos y reducen el ritmo del habla, en otros estudios se señalan características opuestas a las anteriores.

- No se encuentran diferencias significativas en relación con el periodo de latencia (periodo de silencio entre la pregunta y la respuesta), ni con la frecuencia de las pausas realizadas.

- Tienden a realizar menos movimientos de brazos, manos, dedos, pies y piernas.

- No se han encontrado diferencias importantes en cuanto a aversión en la mirada, sonrisas, auto-manipulaciones, cambios de posición o parpadeos.

A pesar de todo en la actualidad no existen evidencias concluyentes sobre el poder predicativo de estos indicadores, no existe un patrón general de comportamiento del mentiroso ya que además de las diferencias individuales también existen las diferencias culturales entre las personas (Saíz Roca et. al., 2006). Tampoco existen procedimientos ni instrumentos estandarizados válidos y fiables para evaluar la credibilidad del testimonio a través de los indicadores conductuales (Masip, Sporer, Garrido, \& Herrero, 2005). 
Instrumentos y técnicas de análisis de la declaración. Estas técnicas se centran en el testimonio en sí mismo más que en el testigo, con lo que se pretende superar los problemas inherentes a los sesgos emocionales y a las diferencias individuales implicados en las líneas de investigación precedentes. Este enfoque considera pues, que la mentira tiene cualidades propias y que son identificables.

Análisis de la Realidad de las Declaraciones. El Análisis de la Realidad de las declaraciones (Statement Reality Analysis, SRA), es un método usado en el ámbito forense y que tiene un amplio uso para asesorar en la credibilidad de testimonio infantil (Vázquez Mesquita, 2007). Este sistema fue creado en Alemania por Undo Undeutsch aplicado principalmente al testimonio de niños presuntas víctimas de abusos sexuales. La validez y fiabilidad de la técnica no han sido comprobadas experimentalmente, aunque el autor considera que no es necesario pues ha sido avalado por cuarenta años de uso en el campo forense (Bembibre Serrano \& Higueras Cortés, 2010). Este sistema fue creado cuando el autor sugirió entrevistar al testigo fuera de la atmósfera judicial, grabar la entrevista y luego analizarla. Undeustch fue el primero en resaltar que las declaraciones basadas en algo ocurrido realmente diferían de aquellas fruto de la imaginación (“hipótesis de Undeustch) (; Howitt, 2009 y Vázquez, 2007)

Posteriormente a este sistema se le incorporó el Análisis de Contenido Basado en Criterios (CBCA) para corroborar la credibilidad del discurso del menor. Ambas técnicas fueron diseñadas originalmente para ser usados en la declaración de menores, pero en la actualidad su uso se ha generalizado en personas de todas las edades.

A grandes rasgos el SRA incluye los siguientes pasos:

- Una entrevista estructurada.

- Realizar el análisis de contenido a la transcripción de la entrevista usando los 19 criterios del CBCA (Criteria-base content analysis). 
- La evaluación de los resultados del análisis de contenido usando una serie de cuestiones sobre validez o no de los resultados del análisis de contenido (Checklist de validez).

Este sistema es usado en un gran número de países europeos y en algunos estados americanos. Especialmente es usado en la evaluación del abuso sexual pues este rara vez se puede determinar con base en evidencia física (Howitt, 2009) (Bembibre Serrano \& Higueras Cortés, 2010)

Para usar esta técnica se debe recolectar información acerca de la competencia general de la persona evaluada para narrar eventos para poder compararlo con la declaración especifica que es de interés forense. Se deben considerar varios elementos en esta técnica para poder evaluar si la declaración del testigo es creíble o no. Estos elementos son esencialmente tres: 1) la competencia del individuo para testificar, 2) la calidad de la declaración del testigo y 3) la confiabilidad de la declaración (Howitt, 2009).

El primer elemento, la competencia del testigo para declarar hace referencia en evaluar si el testigo tiene la competencia cognitiva para declarar (memoria autobiografica, habilidades verbales, habilidades perceptuales). Un testigo que tiene una baja capacidad para dar una narración de eventos recientes de su vida pudiera tener un daño cerebral lo que haría su declaración poco valida. Esta fase da la oportunidad de obtener la línea base de las habilidades del testigo para una buena narración de sus experiencias así como una impresión de las características de sus narraciones.

En segundo lugar la calidad de la declaración es esencialmente el análisis de la declaración basada en criterios (CBCA). Esto se puede realizar evaluando la declaración obtenida del testigo o comparando la declaración dada por el testigo con otras declaraciones en momentos diferentes, como el testimonio dado al ministerio público.

La última fase es evaluar la confiabilidad de la declaración. En ocasiones los testigos darán, sin la intención de hacerlo, declaraciones que se aparten de lo creíble. En esencia esta fase involucra evaluar si el testigo fue sugestionado, ya sea por un 
interrogatorio sugestivo o directivo hecho por otras personas (policías, agentes de investigación, etc.). Esto puede evaluarse buscando evidencia de un estilo de entrevista sugestivo en la denuncia o testimonial, o sí la narración del testigo cambia abruptamente después de una entrevista con otro profesional. Si no hay evidencia de sugestión el CBCA se puede interpretar directamente tomando en cuenta la capacidad del testigo para declarar; en caso de que exista evidencia de sugestión se debe tener cuidado con la evaluación. El CBCA no puede distinguir entre narraciones basadas en la experiencia y aquellas basadas en la sugestión.

Modelos de Control de la Realidad (Reality Monitoring). Existen varias revisiones sobre este método. Johnson y Raye (1981) (Como se citó en Bembibre Serrano \& Higueras Cortés, 2010) describen un modelo de control de la realidad (reality monitoring, RM) que se ocupa de los procesos implicados en la decisión de si una determinada información tenía un origen externo (conformado por elementos perceptivos) o interno (elaborado por el pensamiento o imaginación). Posteriormente Johnson, Hashtroudi y Lindsay (1993) elaboraron por su parte el control de fuentes (source monitoring, SM) que además de determinar el origen de la información (interno o externo) busca distinciones dentro de cada uno de los orígenes (cuando una afírmación es hecha por una u otra persona en determinada situación).

En términos generales se asume que el recuerdo de la información percibida, en comparación con los recuerdos de sucesos imaginados, incluiría más elementos perceptivos (espaciales y temporales), semánticos (detallismo) afectivos (reacciones emocionales) y de apoyo (sobre lo que ocurrió antes y después), y menos elementos relacionados con operaciones cognitivas (Bembibre Serrano \& Higueras Cortés, 2010; Manzanero y Diges, 1994 y Saíz Roca, et. al., 2006).

Existen evidencias de que los testimonios verídicos muestran las características de la información recuperada desde una fuente real, mientras que los falsos se asemejan más a la recuperada a partir de procesos imaginativos o del pensamiento (Masip, Sporer, Garrido, \& Herrero, 2005). Schooler, Clark y Loftus (1988) en Manzanero y Diges (1994) encontraron que el entrenamiento produce una significativa mejora en la discriminación de los relatos reales e imaginados. 
La técnica se basa en el repaso mediante una lista de ocho criterios, de los cuales los siete primeros son criterios de veracidad (las cuales deben aparecer si la declaración es verdadera) y el octavo es un criterio de falsedad, el cual es más fácil de encontrar en declaraciones falsas.

Instrumentos y técnicas psicofisiológicas. Estas técnicas están orientadas al uso de herramientas tecnológicas para medir los cambios fisiológicos del cuerpo, los cuales están relacionados con la mentira.

Polígrafo. A menudo el polígrafo se etiqueta como "detector de mentiras", pero no detecta mentiras sino ciertos cambios periféricos que pueden traslucir ansiedad, miedo, culpa o una respuesta de orientación por parte del examinado. El que estos estados internos se asocien o no con el engaño es otra cuestión. Mentir puede o no dar lugar a ansiedad, miedo, etc., y estas emociones pueden deberse al acto de mentir o bien a otros factores (Garrido, Massip, \& Herrero, 2006).

El polígrafo es una técnica, basada en las respuestas psicofisiológicas del cuerpo relacionadas con las reacciones fisiológicas del mismo al dar una información inventada cuando se le da la instrucción contraria. Comúnmente el polígrafo se utiliza cuando en las investigaciones policiales existen datos que son difíciles de clarificar, pues en ocasiones las declaraciones tanto de los testigos como de los victimarios, pueden omitir cierta información, pues creen que no son importantes (Iacond \& Patrick, 2006).

Los inicios del polígrafo se remontan a principios del siglo XIX con el criminólogo italiano Lombroso, que utiliza el pletismógrafo para medir la velocidad del pulso y el volumen sanguíneo durante los interrogatorios criminales, ya que los cambios en estas áreas se relacionan con cierta deshonestidad en las personas (Clifton, 1991 en Hernández Fernandez y Alonso Quecuty, S.F.). Después del trabajo de Lombrosso el polígrafo tiene dos grandes protagonistas; principalmente en la Universidad de Harvard de los Estados Unidos de América donde tuvo su nacimiento a principios del siglo XX. En 1908 Hugo Munstenberg, profesor de esta universidad e innovador del campo de la psicofisiología y la criminología propuso teóricamente el uso de tres monitores de análisis en 
la detección del estrés emocional parecidos a los utilizados en los polígrafos actuales. Otro precursor fue William Moulton Martson quien desarrolló el primer detector de mentiras específicamente por utilizar el monitoreo de la presión sanguínea para evaluar la deshonestidad entre sospechosos de ilícitos (Benavides, 2007). En 1971 él afirmaba que existe una alta correlación entre las mentiras y los cambios en la presión sanguínea; de igual forma es el primero en hablar del "detector de mentiras" (Clifton, 1991 en Hernández Fernandez y Alonso Quecuty, s/f).

Normalmente los registros poligráficos comprenden la respuesta psicogalvánica, la presión sanguínea relativa, el ritmo cardiaco y la respiración. Para ello es necesario colocar unos electrodos sobre los dedos del sujeto mediante los cuales se tomas las medidas sanguíneas, y unos tubos flexibles alrededor del pecho y del abdomen para las medidas respiratorias (Garrido et. al., 2006; Howitt, 2009 y Muños García, Navas Collado y Graña Gómez, 2003).

En escenarios reales las personas que usan el polígrafo están convencidas de su utilidad, aunque la técnica en sí puede que no sea capaz de distinguir entre la verdad y la mentira, el valor de la misma radica en que las personas en general creen en su eficacia para detectar el engaño, incluyendo a los delincuentes. Por lo tanto, si se dice a un sospechoso que falló en la prueba del polígrafo esto podría llevar a que confiese el delito que cometió. Desafortunadamente también significa que una persona inocente podría dar una confesión falsa, es decir, admitir un delito que no cometió. El mismo autor, menciona que existen un gran número de investigaciones acerca de la validez del polígrafo para la detección de la mentira, la mayoría de estos usan la prueba de pregunta control (Control Cuestion Test en inglés) la cual es la más usada en contextos forenses. Pero la mayor parte de estas investigaciones sobre la validez del polígrafo se han realizado en ambientes de laboratorio, por lo que poseen las siguientes limitaciones: (Howitt, 2009).

- En el ambiente del laboratorio, fallar el examen poligráfico no tiene las mismas consecuencias que en la vida real. Por lo tanto los participantes no tienen una motivación real para mentir. 
- Debido a que no existen consecuencias por fallar el examen poligráfico, los cambios fisiológicos propios del miedo de ser atrapado mintiendo pueden no ser tan intensos como en un escenario real de detección del engaño.

Son pocos los estudios de campo en los que se pueden corroborar los resultados del examen poligráfico con la "verdad objetiva", Patrick y Iacond (1991 como se citó en Howitt 2009), estudiaron todos los casos de una metrópolis canadiense que involucraron el examen poligráfico en un periodo de cinco años. Revisaron los registros de policía para encontrar evidencia de personas que hayan confesado después o casos en los que después se comprobó que el crimen no había ocurrido. Encontraron que solo el $57 \%$ de los casos habían sido identificados correctamente como inocente; no muy alejado del 50\% de probabilidad que equivale a lanzar una moneda para tomar una decisión. Pero encontraron que hubo un $98 \%$ de éxito para identificar correctamente a los individuos culpables. Kleinmuntz y Szucko (1984) y Horvath (1977) realizaron investigaciones donde la verdad objetiva se basó de las confesiones que pudieron estar influencias por los resultados del polígrafo, ellos encontraron que el $76 \%$ y $77 \%$ de los culpables fueron correctamente clasificados, mientras que el $63 \%$ y $51 \%$ de los inocentes fueron clasificados correctamente.

Estas investigaciones fueron hechas analizando exámenes poligráficos que usaron la prueba de pregunta control. Existen otro tipo de pruebas por ejemplo la prueba del conocimiento culpable o Guilty Knowledge Test, Elaad, Ginton y Jungman (1992 en Howitt 2009) encontraron que esta prueba es muy eficiente para identificar a las personas inocentes, las del $90 \%$ de estas fueron identificadas correctamente y solo en el caso de los culpables, solo el $76 \%$ fueron identificados correctamente.

Potenciales Evocados. También conocida como "Brain Fingerprint” fue desarrollada por el neurocientífico, Dr. Lawrence A. Farwell, fundador del "Brain Figerprint Laboratories" en Seattle, Washington.

Esta técnica de análisis fisiológica se basa en el estudio de la actividad eléctrica de distintas áreas del cerebro, en respuesta a cierta información (generalmente visual) que se muestra al sujeto (Saíz Roca et al., 2006). Los potenciales evocados son picos que 
aparecen en el electroencefalograma (EEG), como respuestas a un acontecimiento discreto como la presentación de un estímulo. Uno de estos picos es llamado P300 o P3, este aparece ante estímulos llamativos o significativos para el sujeto (Garrido et al., 2000; Saíz Roca, et al., 2006)

Se basa en el precepto de que cuando reconocemos una imagen que hemos visto anteriormente, nuestro cerebro produce un tipo de ondas eléctricas que son distintas a las producidas cuando observamos una imagen por primera vez, es decir, en el primer caso existe una huella de memoria previa y en el segundo no (Saíz Roca, et al., 2006).

Rosenfeld (2002) indica tres aspectos del P300 que son relevantes en tareas de conocimiento oculto. Primero la amplitud, es decir, la altura de la onda; el segundo es el perfil, es decir, la distribución de amplitudes en las zonas parietal, central y frontal. El tercer aspecto relevante es la latencia, es decir, el tiempo que tarda la onda en aparecer desde la presentación del estímulo. El P300 ha demostrado ser útil para discriminar entre verdades y mentiras en tres paradigmas experimentales distintos: a) simulación de pérdida de memoria; b) conocimiento oculto de objetos robados y de realización de actos ilegales; y c) detección de memorias falsas.

Análisis de Estrés de Voz. Los Analizadores de Estrés de Voz (VSA) tienen una larga historia de desarrollo, la cual comenzó en 1970 con diferentes individuos y compañías compitiendo por alcanzar la última tecnología para ser introducida al mercado (Damphouse, Pointon, Upchurch, \& Moore, 2007). El análisis de estrés de voz se origina del concepto de que cuando una persona está bajo estrés, especialmente cuando el entrevistado está bajo “jeopardy”, el cuerpo se prepara para pelear incrementando la reacción de los músculos para brincar a la acción (Xianfeng, 2005).

En el año de 1971, Olof Lippold, investigador de la Universidad College London, quien publicó en la gaceta "Scientific American" los resultados de su investigación, llamada Tremores Fisiológicos, la cual se basaba en los trabajos iniciados una década antes por los doctores Martin Holliday y Joseph Redfearn en el hospital Nacional de Londres. (Benavides, 2007). Holliday y Redfearn 
habían descubierto en la zona de la laringe la contracción de un musculo voluntario que era acompañado por tremores de diminutas oscilaciones. Años después descubrieron que la mayoría de este tremor fisiológico consistía en la oscilación de un mecanismo reflejo involuntario con frecuencias entre 8 y 12 Hertz que controlaba la tensión de los músculos estriados alrededor de las cuerdas vocales. (Benavides, 2007).

El proceso del VSA para detectar el engaño es similar al usado en las pruebas poligráficas. Los examinadores del VSA usan entrevistas pre-test para preparar al sujeto para la prueba real. El propósito de este proceso es establecer la credibilidad de los procedimientos de la prueba, desarrollar el rapport con el sujeto, hacer observaciones de la conducta del entrevistado, crear preguntas para la prueba y romper cualquier barrera internalizada por el sujeto al hacer admisiones (Hopkins, Benincasa, Rattley, \& Grieco, 2005).

El software de los programas de VSA está diseñado para medir los cambios en los patrones de voz causados por el estrés, o el esfuerzo físico, o por tratar de ocultar respuestas engañosas. Los programas de VSA interpretan los cambios en los patrones de voz e indican por medio de una gráfica si el sujeto está siendo "deshonesto" u "honesto" (Damphouse, S.F.)

Error de Otelo y Error de Brokaw: Estos errores, involucran grandes riesgos para el que realiza una evaluación de la credibilidad, son más comunes en las técnicas de la corriente psicofisiológica y de los indicadores conductuales de la evaluación (Bembibre Serrano \& Higueras Cortés, 2010)

Técnicas e instrumentos para recuperar el testimonio 
Protocolo de Entrevista Forense de Michigan: en su tercera edición del 2010, tiene como objetivo obtener la declaración de un niño, considerando el desarrollo infantil, imparcial y búsqueda de la verdad de manera, que apoyará la toma de decisiones precisa y justa en el de la justicia penal y los sistemas de bienestar infantil.

Elaboración Narrativa (Saywitz y Snyder, 1996): técnica que consta de las siguientes fases:

1. Entrenamiento en la elaboración narrativa

a. Se explica al menor las razones para utilizar nuevas formas para mejorar el recuerdo.

b. Se dan instrucciones para que su descripción se lo maás completa posible

c. Se explica la estrategia para organizar e informar en detalle el recuerdo con base a cinco categorías (participantes, ambiente, acciones, conversación y estados afectivos, consecuencias).

d. Se le entregan tarjetas recordatorias (señales visuales) de cada categoría.

e. Se practica la estrategia con situaciones simuladas, en la cual se retroalimenta positivamente y modela las respuestas del menor.

f. Se le recuerdan las instrucciones antes de comenzar la entrevista.

2. Recuerdo libre

3. Recuerdo guiado: da la oportunidad al menor de elaborar el contenido de su declaración entregada, lo que se facilita presentando tarjetas de colores.

4. Preguntas aclaratorias: debiendo hacer solo las que se estime oportunas. 


\section{Capítulo 2. Metodología}

En el presente trabajo de tesis se usó el método mixto, debido a que Hernández Sampieri, Fernández Collado y Baptista Lucio (2010) afirman que este método presenta las siguientes ventajas:

a) Da la capacidad de tener una perspectiva más amplia y profunda del tema que se va a investigar,

b) Tiene la bondad de permitir apoyar con mayor solidez las inferencias científicas.

c) Permite una mejor exploración y explotación de los datos.

\subsection{Objetivos}

Objetivo general. Desarrollar una de protocolo para la toma del testimonio de niños, niñas y adolescentes por un equipo interdisciplinario en el sistema penal oral y acusatorio.

\section{Objetivos específicos}

- Analizar la legislación acorde al tema para que el protocolo propuesta tenga sustento jurídico.

- Revisión de investigaciones en niños y adolescentes sobre las características que influyen en la calidad de su testimonio.

- Conocer la opinión de profesionales, que se desempeñan en el sistema penal acusatorio oral, sobre la pertinencia de la propuesta del protocolo.

- Diseñar la propuesta de protocolo para la toma de declaración por un equipo multidisciplinario.

- Evaluar la pertinencia de la propuesta del protocolo a través de la opinión de profesionales del ámbito privado y público que se desempeñan dentro del sistema penal acusatorio oral. 
- Realizar las correcciones a la propuesta del protocolo.

\subsection{Preguntas de investigación}

1.- ¿Cuáles son las principales problemáticas existentes en la toma del testimonio dentro del sistema penal oral acusatorio? (CUAN)

2.- ¿Cuál es la percepción de los expertos entrevistados sobre la utilidad de la creación de una propuesta de protocolo para la toma de testimonio por un equipo multidisciplinario en el sistema penal oral acusatorio? (CUAL)

\subsection{Participantes}

Fase cualitativa: revisión de documentos científicos, libros, artículos, leyes internacionales, nacionales y locales para construcción de las fases del protocolo.

Fase cuantitativa (desarrollo y revisión del protocolo por parte de expertos): se usó un muestreo no probabilístico por criterio, muestra cautiva convocados a un curso de "Justicia Terapéutica", participaron 64 profesionales de diferentes áreas (47 licenciados en derecho, 4 psicólogas y una trabajadora social) que se desempeñan en el área penal del sistema de justicia (con al menos dos años de experiencia) y que ayuden a realizar la revisión y corrección del protocolo.

\subsection{Tipo de Estudio y Diseño}


En el presente trabajo de tesis, como ya se mencionó, se usó una metodología mixta debido a que esta ofrece una visión más amplia el momento de estudiar un fenómeno y ya que la toma del testimonio contempla una amplia cantidad de variables que pueden afectar el resultado de esta procedimiento, se eligió esta aproximación metodológica para poder abordar el fenómeno de estudio en su totalidad (Hernández Sampieri, et al., 2010).

Se usó un diseño exploratorio secuencial (DEXPLOS) de modalidad derivativa pues en una primera fase se recolectaron datos cualitativos para construir el protocolo y posteriormente se recolectarón datos cuantitativos para evaluar la utilidad y eficacia del protocolo. Esta modalidad implica tres etapas: 1) recabar datos cualitativos y analizarlos (para la creación del protocolo) 2) utilizar los resultados para construir un instrumento cuantitativo (crear el protocolo) y 3) someter el instrumento a un proceso de evaluación para validarlo (evaluación del protocolo) (Hernández Sampieri, et al., 2010).

\subsection{Instrumentos, materiales y/o técnicas}

\section{Instrumentos}

Protocolo para el testimonio de niños y adolescentes por un equipo interdisciplinario: este instrumento se creó con base en la revisión de literatura científica sobre las técnicas e instrumentos que son más usados en la evaluación de la credibilidad del testimonio, así como la revisión de los diversas leyes internacionales, nacionales y locales que sustentan la creación de dicho protocolo (ver apéndice A).

Cuestionario para la evaluación de protocolo: son formas impresas en las cuales los sujetos proporcionan información escrita al investigador. Permite que las respuestas sean más fáciles de catalogar y que las respuestas puedan ser cuantificadas (Arias Galicia, 
2012). Se usará un cuestionario dicotómico en que se darán a los participantes dos alternativas: responder afirmativamente o negativamente a cuestiones relacionadas con el protocolo. Dicho cuestionario tendrá como finalidad que las instituciones y autoridades que revisen el protocolo lo califiquen de acuerdo con la utilidad, pertinencia y facilidad de aplicación.

\section{Técnicas}

Análisis de Contenido: conjunto de técnicas de análisis de las comunicaciones tendentes a obtener indicadores (cuantitativos o no) por procedimientos sistemáticos y objetivos de descripción del contenido de mensajes permitiendo la inferencia de conocimientos relativos a las condiciones de producción/recepción (contexto social) de estos mensajes (Bardin, 1996, como se citó en Andréu Abela, s.f.).

\subsection{Procedimiento}

\section{Fase Cualitativa}

Búsqueda de información. En la primera fase de esta tesis se revisaron investigaciones científicas referentes a la evaluación de la exactitud del testimonio y se analizó la información obtenida para encontrar los factores o características que pueden afectar la exactitud del testimonio; se agruparon las características encontradas en factores de acuerdo a sus similitudes. Al mismo tiempo se hizo una revisión de las leyes, tratados, protocolos y directrices que se encuentren vigentes en el territorio mexicano y que regulan las acciones a realizar para la toma de un testimonio.

Diseño: Posteriormente se realizó el diseño del protocolo considerando los factores encontrados en la revisión y análisis de información. 


\section{Fase Cuantitativa}

Evaluación cuantitativa del protocolo. Se aplicó un cuestionario, construido específicamente para el proceso (ver apéndice B), para que instancias gubernamentales y autoridades inmersas en el proceso penal acusatorio y oral evalúen las cualidades positivas y negativas

Corrección y adecuación del protocolo. Una vez analizadas las evaluaciones realizadas hacia el protocolo se realizaron las correcciones y adecuaciones pertinentes.

\subsection{Análisis de resultados}

Fase cualitativa. Para esta fase se realizó un análisis de contenido de la información encontrada. El análisis de contenido se define como una técnica para hacer inferencias sobre un texto focal sobre su contexto social de una manera objetiva (Bauer, 2010).

Fase cuantitativa. Para esta fase, se realizó un análisis de las frecuencias de las respuestas obtenidas en el cuestionario para evaluar el protocolo del testimonio para poder describir de manera general cómo las instancias y autoridades calificaron el protocolo en cuanto su utilidad, pertinencia y facilidad de aplicación. 


\section{Capítulo 3. Resultados}

\section{Fase cualitativa}

Para esta fase se generaron tres categorías para diferenciar la información encontrada. La primera se refiere a las legislaciones que sustentan la pertinencia del protocolo para recuperar el testimonio; la segunda hace referencia a todas aquellas normas y protocolos que establecen líneas de acción sobre la participación de niños, niñas y adolescentes en el sistema de justicia; y por último, la tercera categoría se refiere a la información proporcionada por la psicología sobre la participación de los niños en el sistema de justicia. En las tablas 1, 2 y 3 se presenta la información encontrada para las categorías: "Legislación", "Protocolos y Normas” y "Aportaciones de la Psicología" respectivamente.

\section{Tabla 1.}

Información encontrada en la categoría "Legislación".

\begin{tabular}{|c|c|}
\hline \multicolumn{2}{|r|}{ Legislación } \\
\hline Documento legal & Información relevante para la toma de testimonio \\
\hline Convención de los Derechos del Niño & Principio de interés superior del niño \\
\hline & Principio de no-discriminación \\
\hline & Principio de derecho a la vida. \\
\hline $\begin{array}{l}\text { Convención Americana sobre los } \\
\text { Derechos Humanos }\end{array}$ & $\begin{array}{l}\text { Art. 9: todo niño tiene derecho a las medidas de protección que en su condición de menor requieren por parte de la } \\
\text { familia, de la sociedad y del Estado. }\end{array}$ \\
\hline Directrices sobre la Justicia en Asuntos & Derecho a un trato digno y respetuoso \\
\hline Concernientes a Niños Víctimas y Testigos & Derecho a la protección contra la discriminación. \\
\hline de Delitos & Derecho a ser informado. \\
\hline & Derecho a ser oído y expresar opiniones y preocupaciones. \\
\hline & Derecho a una asistencia eficaz. \\
\hline & Derecho a la intimidad. \\
\hline & Derecho a ser protegido de sufrimientos durante el proceso de justicia. \\
\hline & Derecho a la seguridad. \\
\hline & Derecho a la reparación. \\
\hline & Derecho a medidas preventivas especiales. \\
\hline
\end{tabular}


Declaración de los Derechos del Niño los Niños, Niñas y Adolescentes.

Tabla 2. (Continuación)

Código Nacional de Procedimientos

Penales

Código Procesal Penal para el Estado de Yucatán
Principio 2: los niños deben gozar de protección especial y disponer de oportunidades y servicios, con el fin de que se desarrolle física, mental, moral, espiritual y socialmente.

Principio 8: el niño debe en todas circunstancias, figurar entre los primeros que reciban protección y socorro.

Art. 3: la protección de los derechos de niñas, niños y adolescentes tiene como objetivo, asegurar un desarrollo pleno, integral, lo que implica la oportunidad de formarse física, mental, emocional, social y moralmente.

Art 3. Los principios rectores de los derechos de niños, niñas y adolescentes son: interés superior de la infancia, nodiscriminación, igualdad, tener una vida libre de violencia.

Art. 14: Niñas, niños y adolescentes tienen derecho a que se les asegure prioridad en el ejercicio de todos sus derechos.

Art. 109, inciso XXVI: se debe resguardar la identidad del niño, niña o adolescente y el Órgano jurisdiccional o el Ministerio Público el principio de interés superior del niño.

Art. 275: cuando deban realizarse diferentes peritajes a personas agredidas sexualmente..., deberá integrarse un equipo interdisciplinario, con profesionales capacitados en atención a víctimas, con el fin de concentrar en una misma sesión las entrevistas que ésta requiera, para la elaboración del dictamen respectivo.

Art. 87: será labor de los fiscales investigadores durante todo el proceso adoptar medidas o solicitarlas, para proteger a los testigos y víctimas de los delitos, facilitar su intervención en el mismo y evitar o disminuir cualquier perturbación que hubieran de soportar...

Art. 100, inciso VI: recibir del Estado asesoría jurídica, atención médica, psicológica y protección especial de su integridad física psíquica

Art. 249: Cuando deban realizarse diferentes peritajes a... menores de edad, deberá integrarse un equipo interdisciplinario con el fin de concentrar en una misma sesión las entrevistas que requiera la víctima. ... el equipo de profesionales deberá elaborar un protocolo y designará, cuando lo estime conveniente, a uno de sus miembros para que se encargue de plantear las preguntas.

Art. 273: La cadena de custodia iniciará donde se descubran, encuentren o levanten los indicios u objetos, instrumentos o productos del hecho delictuoso y finalizará por orden de autoridad competente.

Los elementos recogidos durante la investigación serán conservados bajo custodia del Ministerio Público, quien deberá adoptar las medidas necesarias para evitar que se alteren de cualquier forma. La cadena de custodia se aplicará teniendo en cuenta los siguientes factores: identidad, estado original, condiciones de recolección, preservación, embalaje y traslado; lugares y fechas de permanencia y los cambios que cada custodio haya realizado. 
Tabla 3.

Información relevante para la toma del testimonio de la categoría "Protocolos y Normas".

\begin{tabular}{ll}
\hline & \multicolumn{1}{c}{ Protocolo y normas } \\
\hline \multicolumn{1}{c}{ Nombre del Protocolo } & \multicolumn{1}{c}{ Información relevante para la toma de testimonio } \\
\hline $\begin{array}{l}\text { Pejocolo Iberoamericano de Actuación Judicial para } \\
\text { Discapacidad, Migrantes, Niñas, Niños, Adolescentes, } \\
\text { Comunidades y Pueblos Indígena. }\end{array}$ & $\begin{array}{l}\text { Medidas para facilitar el testimonio: los jueces deberán adoptar y aplicar las medidas pertinentes para } \\
\text { personal especializado o los padres acompañen a los menores cuando den su testimonio. } \\
\text { Idioma e intérprete: el proceso de la toma de testimonio debe realizarse en un idioma sencillo y } \\
\text { comprensible para niñas, niños y adolescentes. }\end{array}$ \\
$\begin{array}{ll}\text { Protocolo de Actuación para quienes imparten Justicia } \\
\text { en Casos que Involucren Niñas, Niños y Adolescentes. }\end{array}$ & $\begin{array}{l}\text { Preparación del niño para participar sin temor: previo al proceso a realizarse se debe explicar al menor } \\
\text { en un lenguaje claro y sencillo en que constará el proceso. }\end{array}$
\end{tabular}

en Casos que Involucren Niñas, Niños y Adolescentes.

en un lenguaje claro y sencillo en que constará el proceso.

Tabla 4. (Continuación)

Testificación: es importante que ningún niño sea obligado a testificar contra su voluntad o sin el conocimiento de sus padres o tutores, con excepción de que estos sean los probables autores del delito cometido contra el niño o si la patria potestad o custodia es cuestionada.

Exhorto a decir verdad: el juez, magistrado y personal especializado de apoyo deben asegurarse que el niño entienda y manifieste a su modo que se conduce o conducirá con la verdad.

Presencia de personal capacitado: se procurará que en toda declaración, ampliación o plática sostenida con el niño se cuente con la presencia de personal capacitado en la atención especializada a niños.

Requerimientos metodológicos: ...se debe cuidar que la metodología usada esté basada en las características de desarrollo del niño, debe permitir la narrativa libre por parte del niño, debe contemplar la adecuada elaboración de preguntas para el esclarecimiento del hecho, contemplar el uso de adecuado de materiales de apoyo para la expresión del niño y contemplar estrategias para el manejo de la tensión y estrés del niño, así como la detección y manejo de mecanismos de defensa psicológicos. 
Registro de la participación del niño: toda actuación infantil deberá ser grabada en audio e imagen en su totalidad.

Valoración del dicho infantil: dicha valoración se realizará tomando en cuenta sus derechos y su grado de desarrollo, deberá hacerse considerando los criterios de credibilidad y las condiciones en las que fue tomada dicha declaración y su posible afectación sobre la actuación del niño.

\section{Tabla 5.}

Información relevante para la toma del testimonio de la categoría "Aportaciones de la Psicología".

\begin{tabular}{|l}
\hline Concepto Psicológico \\
\hline Variables a estimar
\end{tabular}

\section{Aportaciones de la Psicología}

\section{Información relevante para la toma de testimonio}

Condiciones de iluminación. Los bruscos en las condiciones de iluminación pueden causar un pobre sensibilidad visual. Los testigos presenciales que han sido sometidos a cambios bruscos en las condiciones de iluminación durante el suceso pueden tener dificultades para percibir adecuadamente los hechos

Duración del suceso. El tiempo de exposición al suceso es un factor importante para in mejor rendimiento de la memoria, a mayor duración del suceso, este podrá ser mejor percibido y codificado

Violencia del suceso. Algunos estudios sugieren que la violencia de un suceso puede dificultar la capacidad de un sujeto para percibirlo y recordarlo. Otros estudios aseveran que la violencia de un suceso puede distorsionar las percepciones ocurridas desde el inicio de la violencia.

Tabla 6. (Continuación)

Estrés y miedo. La ley de Yerkes-Dodson sugiere que el nivel de rendimiento aumentará a veces y disminuirá en otras ocasiones por los aumentos de estrés. De acuerdo a esta ley existe un nivel óptimo de estrés en que el rendimiento de un sujeto es mejor.

Focalización en el arma. Un efecto del estrés consiste en que se reduce la atención, de tal forma que las personas se concentran en ciertas características de su entorno y, consecuentemente, prestan menos atención a otras características. Este fenómeno de focalización en el arma alude a la concentración de la atención del testigo en un arma y a la resultante reducción en la habilidad para recordar otros detalles del crimen

Estrés crónico. Alude a un estado de ansiedad causada por ciertos sucesos vitales estresantes. El estrés crónico puede causar preocupación de modo que los individuos no prestan atención a los estímulos de su entorno, pudiendo perder información importante y necesaria para un recuerdo preciso

Expectativas y estereotipos. La memoria de los testigos está influenciada por los conocimientos y experiencias adquiridas. Se ha comprobado que si un testigo no puede precisar algún tipo de información, recurre a los estereotipos. 
Edad. En general los niños ofrecen una información más limitada que los adultos, pero lo que dicen no es menos exacto. También se cree que los niños más pequeños son más sugestionables, en varios estudios se ha visto que los niños menores de tres años son más sugestionables que los adultos, sin embargo en investigaciones con niños mayores de cinco años no se han encontrado diferencias en la sugestionabilidad de los niños y los adultos.

Sexo: Con respecto a esta variable las investigaciones muestran que en general el sexo de los testigos no afecta a su memoria

Entrenamiento. Esta variable se refiere al grado en que una persona en virtud de su empleo, experiencia o entrenamiento, puede ser mejor testigo que otra. El entrenamiento puede aumentar la probabilidad de que un testigo haga un esfuerzo deliberado durante el proceso para prestar atención a los detalles y tratar de recordarlos.

Olvido. Son muy conocidas las investigaciones de Ebbinghaus sobre el olvido y como sus resultados dieron origen a la llamada "curva del olvido", la cual muestra que los sujetos olvidan una gran parte de la nueva información poco después de aprenderla y posteriormente el olvido se va haciendo más gradual. Aplicado al testimonio es obvio que en cuanto más tiempo pase entre el hecho presenciado y la primera declaración, más deterioro existirá en el recuerdo de los sucesos

Información postsuceso. Durante la retención del evento, las experiencias posteriores al suceso pueden afectar a la memoria del suceso original, alternando o trasformando el recuerdo de este.

Métodos de interrogación. Numerosas investigaciones dan cuenta que el tipo de preguntas realizadas en los interrogatorios a testigos pueden inducir el recuerdo de cosas que nunca has estado presentes. Para reconstruir el recuerdo del testigo de manera eficaz el entrevistador debe conocer las formas en que la evocación del recuerdo puede verse afectada por distintos métodos de elicitación. Los investigadores han sugerido que se obtendrían buenos resultados con una estrategia de interrogatorio que primero permita una narración libre para después hacer preguntas específicas, teniendo mucho cuidado con la forma en que se realiza la pregunta (evitar preguntas sugestivas o inductoras)

Recuperación múltiple. La cantidad de veces que un testigo ha tenido que recuperar un suceso, es uno de los factores importantes de distorsión que se deben de tener en cuenta al analizar la exactitud del recuerdo del testigo.

Tiempo transcurrido desde el suceso. La preparación juega un papel determinante en la calidad del recuerdo, mientras más tiempo pase entre el suceso y la declaración la persona puede construir el recuerdo, lo que dificulta la capacidad de los evaluadores de determinar correctamente si un recuerdo es real o imaginario.

\section{Fase cuantitativa}

A continuación se presentan los resultados obtenidos de la aplicación del cuestionario de evaluación del protocolo para la recuperación del primer testimonio en niñas, niños y adolescentes; se analizarán primeramente las medias de puntuaciones para cada etapa del protocolo y posteriormente se describirán las puntuaciones dadas por los participantes a cada fase.

Tabla 7 .

Medias aritméticas de las puntuaciones.

Fase del protocolo Media de la calificación


Protocolo para el Testimonio en Niños y Adolescentes

\begin{tabular}{cc}
\hline Acreditación del delito & 4.27 \\
Preparación del menor de edad y de los padres & 4.45 \\
Adecuación del espacio físico & 4.27 \\
Preparación de equipo de video & 4.47 \\
Valoración para toma de decisiones & 4.33 \\
Rapport & 3.94 \\
Establecimiento de reglas & 4.31 \\
Verdad/mentira & 4.75 \\
Práctica y memoria & 4.37 \\
Narrativa libre & 4.17 \\
Clarificación de dudas & 4.44 \\
Reformulación de preguntas & 4.14 \\
Cierre & 4.17 \\
Las fases sirven para cumplir con el objetivo & 3.94 \\
\hline
\end{tabular}

En la tabla 4, se observan las medias de las calificaciones para cada una de las fases propuestas en el protocolo para 1 toma de testimonio. 
Como se observa en la tabla 4, las medias de los resultados obtenidos en cada una de las escalas fueron mayores a 4.00, siendo la máxima puntuación 5.00 y la calificación menor de 1.00. Las únicas categorías con menos de 4.00, fueron la fase de "Rapport" y el reactivo final: "Las frases sirven para cumplir con el objetivo".

A continuación se describirán las frecuencias de las calificaciones para cada una de las categorías.

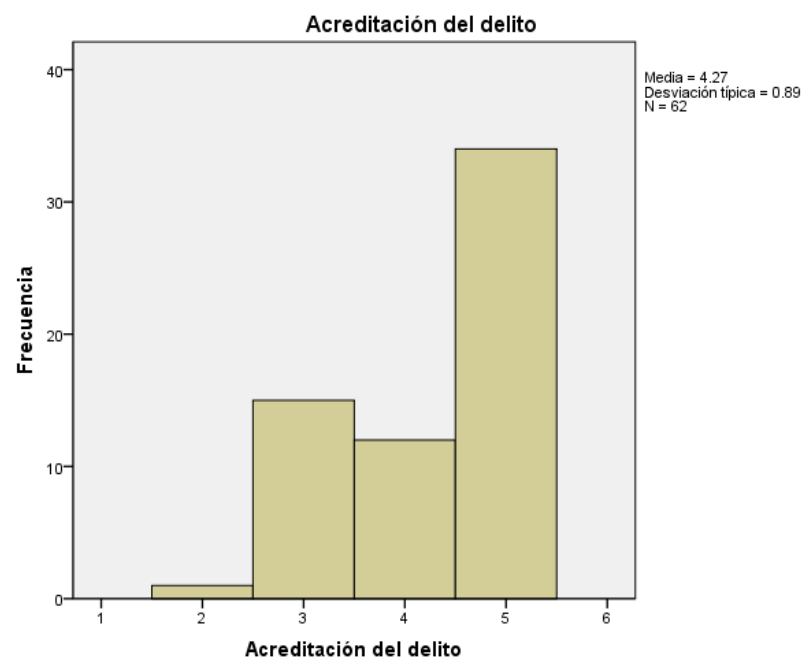

Figura 1: Frecuencia de las respuestas para la fase "Acreditación del delito".

Como se observa en la figura 1, la puntuación media fue de 4.27, lo cual indica que los participantes consideran muy necesario que se realice la distinción del delito que se investigará antes de realizar la toma de testimonio con los menores de edad.

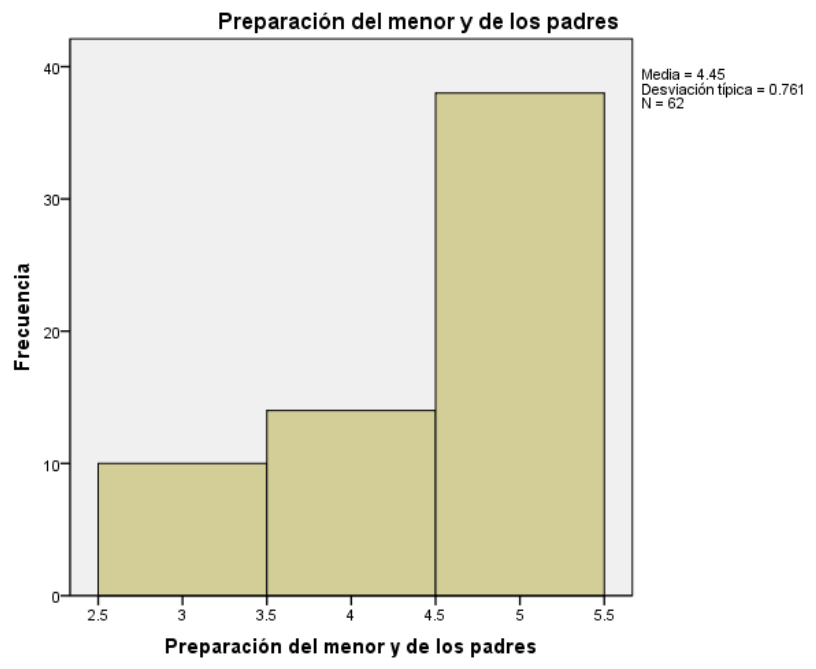

Figura 2: Frecuencia de las respuestas para la fase "Preparación del menor y de los padres". 
La media de calificaciones en la categoría "Preparación del menor y de los padres" fue de 4.45 siendo la respuesta más común "Totalmente Necesario", por lo que se infiere que los participantes consideraron que contextualizar al menor de edad sobre el proceso así como a los padres es algo que se debe realizar en cualquier toma del testimonio.

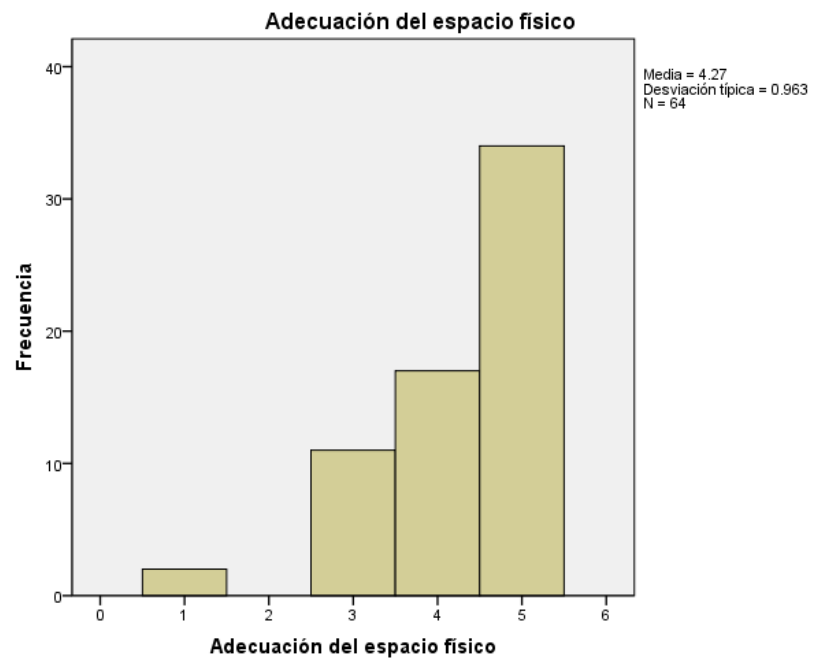

Figura 3: Frecuencia de las respuestas para la fase "Adecuación del espacio físico".

Esta categoría hace referencia a la necesidad de cuidar las características del espacio físico donde se realiza la toma de testimonio, la media de calificación fue de 4.27, lo que indica que la mayoría de los participantes están de acuerdo con adecuar las condiciones del lugar del testimonio antes de recuperar el testimonio. 


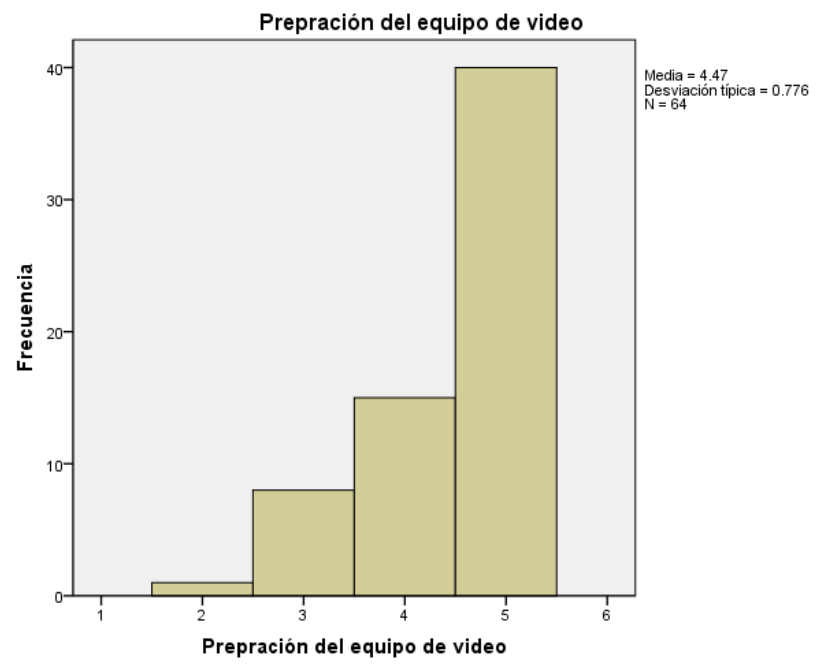

Figura 4: Frecuencia de las respuestas para la fase "Preparación del equipo de video".

La media de las respuestas a esta categoría fue de 4.47, esta categoría se refiere a la necesidad de usar equipo de video para capturar el proceso de recuperación del testimonio, por los resultados obtenidos se observa que la mayoría de los participantes consideran de mucha utilidad el realizar la grabación de video de las sesiones de la toma de testimonio.

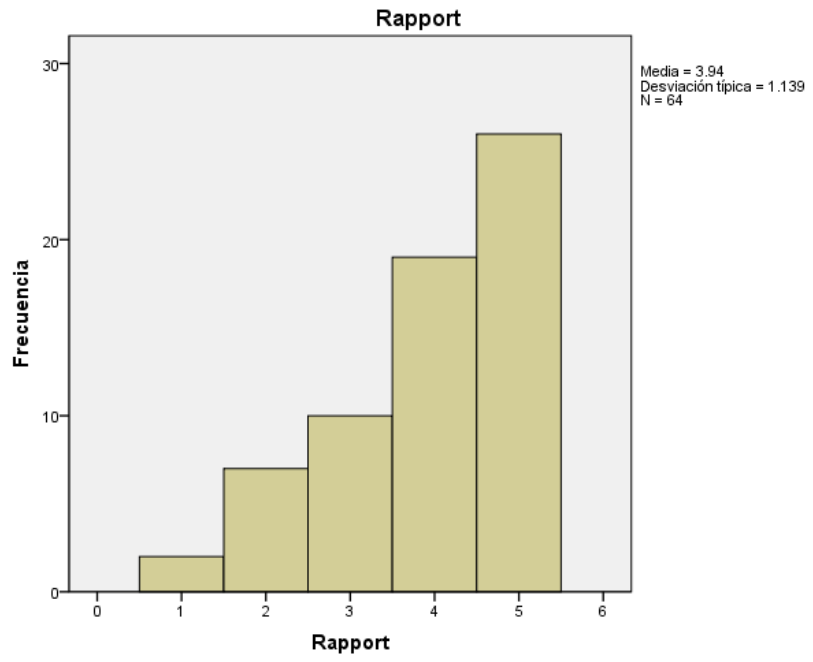

Figura 5: Frecuencia de las respuestas para la fase "Rapport".

La puntuación media para esta fase fue de 3.94, aunque no es una calificación baja, en comparación con las demás fases esta fase es la que obtuvo la menor puntuación por los 
participantes, debiendo considerar si esta fase del protocolo deba seguir dentro del protocolo para la toma del testimonio.

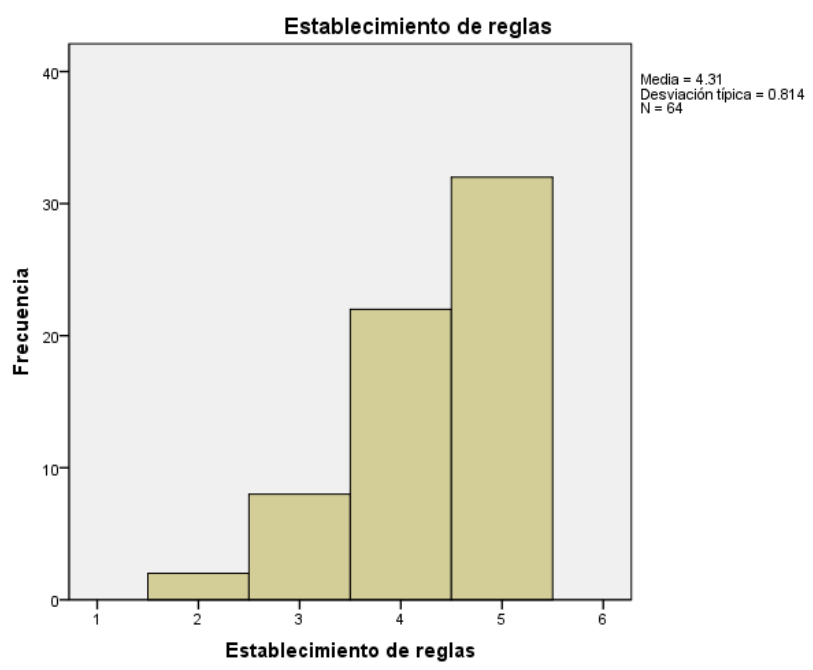

Figura 6: Frecuencia de las respuestas para la fase "Establecimiento de reglas".

Como se observa en la tabla 6, la media de las respuestas de los participantes fue 4.31 por lo que se considera que el establecer reglas con los menores de edad es algo importante y necesario en la toma de testimonio.

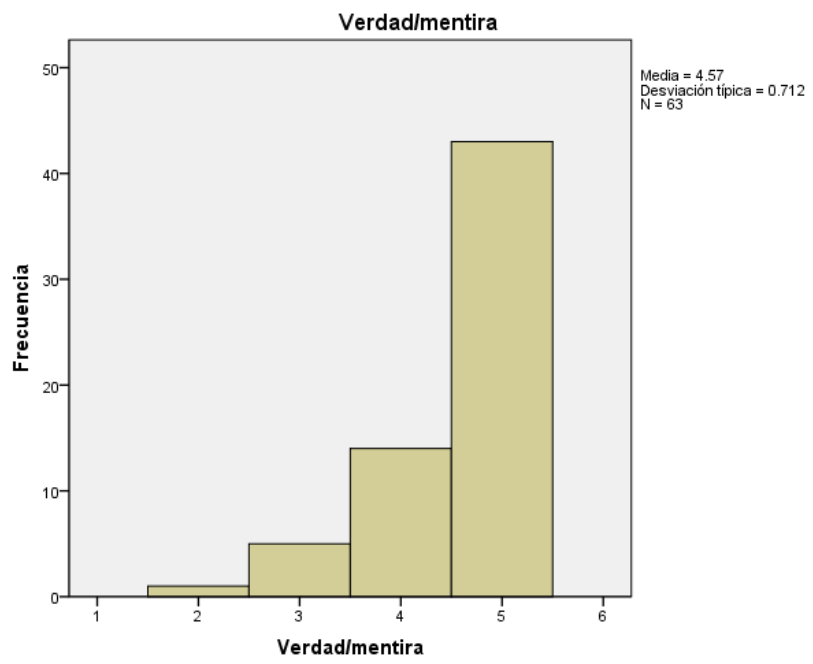

Figura 7: Frecuencia de las respuestas para fase "Verdad/mentira". 
La tabla 7 presenta las puntuaciones para la fase "Verdad/mentira", en esta fase se evalúa la capacidad de los menores de edad de comprender la diferencia entre decir la verdad y decir mentiras. La media de las respuestas fue de 4.57, esto indica que es para los participantes esta fase es muy necesaria.

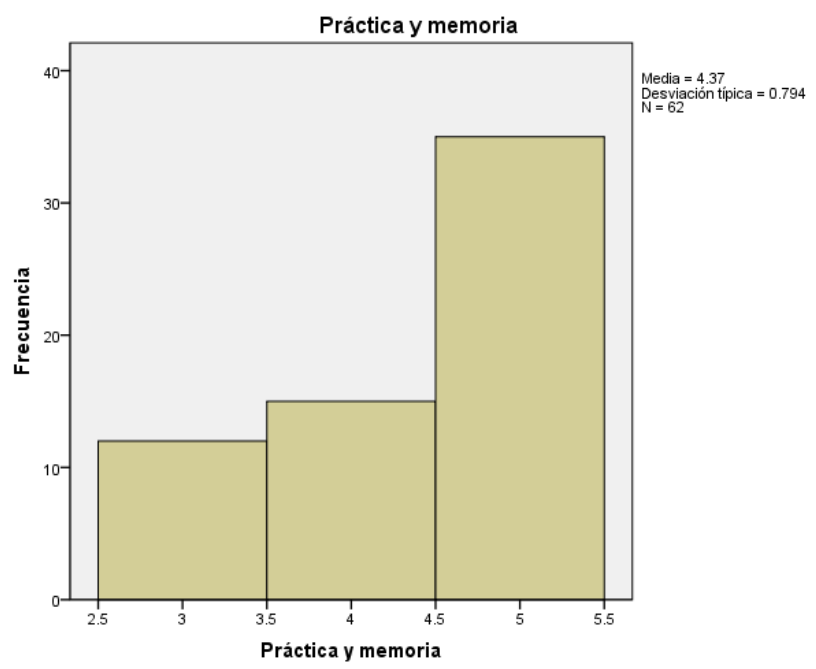

Figura 8: Frecuencia de las respuestas para la fase "Práctica y memoria".

Como se puede ver en la tabla 8, la mayoría de los participantes calificaron esta fase como "Muy necesaria", lo cual indica que esta fase del protocolo para la toma de testimonio, debe considerarse dentro del esquema final del protocolo.

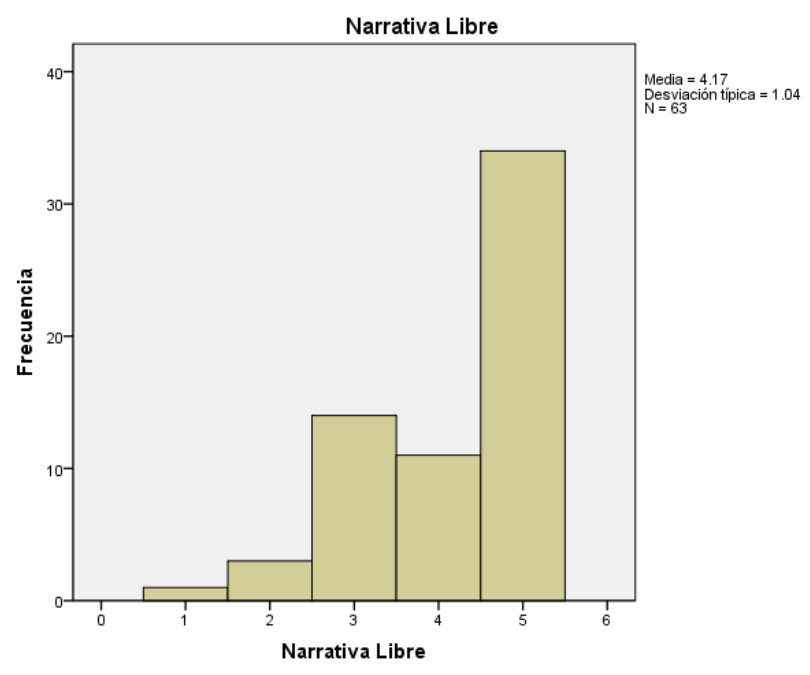

Figura 9: Frecuencia de las respuestas para la fase "Narrativa Libre". 
La tabla 9, presenta las puntuaciones para la fase de "Narrativa Libre", la mayoría de los participantes calificaron esta fase como "Totalmente necesaria" dentro del esquema del protocolo para la toma de testimonio.

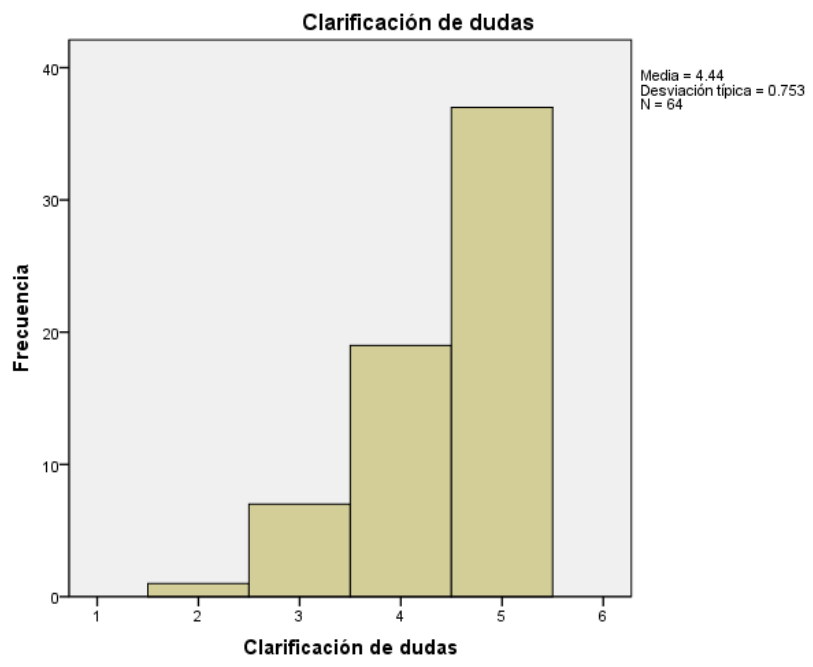

Figura 10: Frecuencia de las respuestas para la fase "Clarificación de dudas".

La tabla 10, muestra los resultados para la fase "Clarificación de dudas", donde se realiza el interrogatorio al menor de edad, para aclarar toda la información que no quede del todo clara durante la fase de narrativa libre.

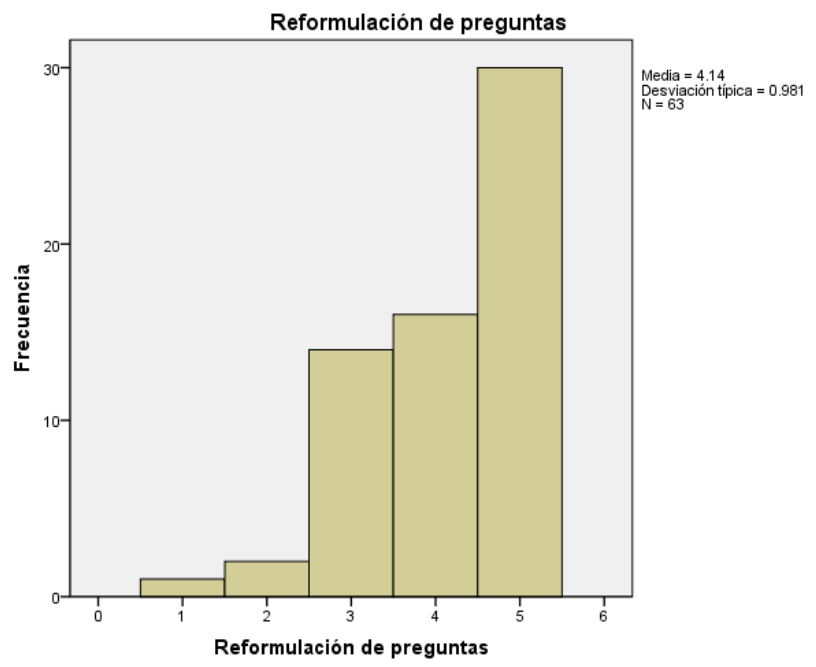

Figura 11: Frecuencia de las respuestas para la fase "Reformulación de preguntas". 
En la tabla 11, se observan los resultados para la fase "Reformulación de preguntas", la media de las puntuaciones fuer de 4.14, esta calificación comparada con las demás fases es menor, por lo que puede ponerse en consideración la presencia de esta fase en el protocolo.

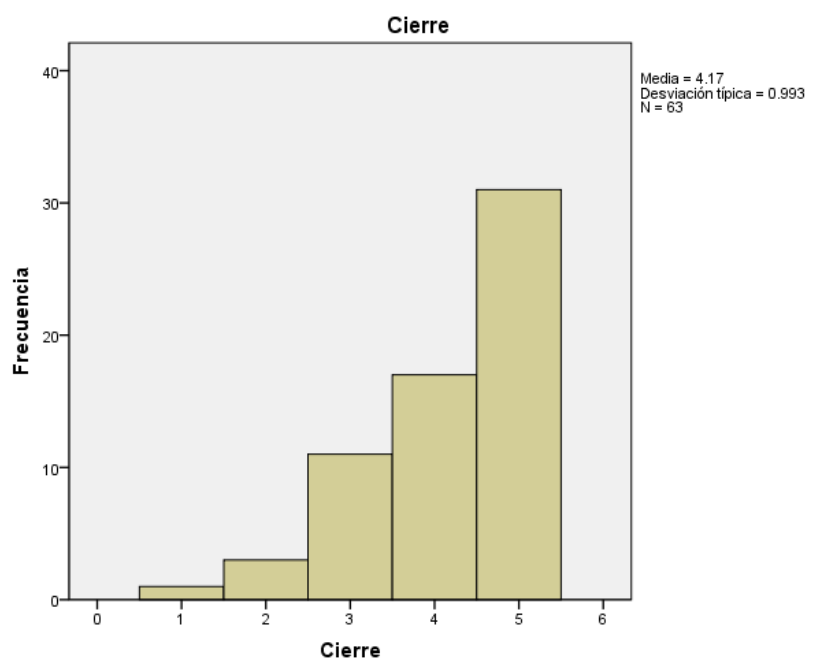

Figura 12: Frecuencia de las respuestas para la fase "Cierre".

La tabla 12, muestra los resultados de las puntuaciones para la fase "Cierre", esta parte del protocolo involucra hablar con el menor de edad de otros temas alejados del caso para que el término del proceso de toma de testimonio no se abrupto.

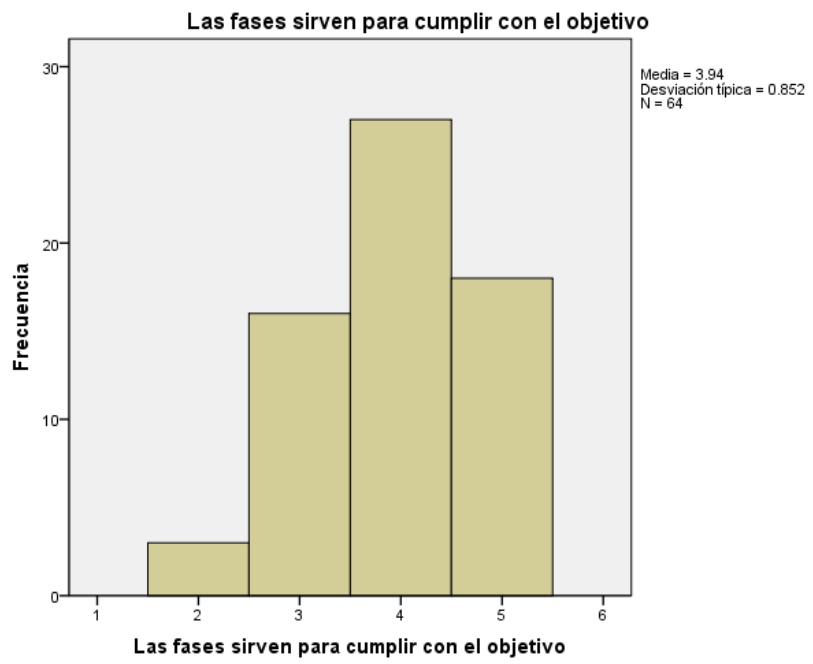

Figura 13: Frecuencia de las respuestas para la pregunta "Las fases sirven para cumplir con el objetivo". 
La tabla 13 presenta los resultados a la pregunta "Las fases sirven para cumplir con el objetivo", esta pregunta buscaba explorar si lo participantes consideran que las fases propuestas son las necesarias para poder cubrir con el objetivo del protocolo; esta fase al igual que la fase "Rapport" fue de las más bajas en comparación con las demás, con una puntuación media de 3.94, aunque los esto parece indicar que los participantes consideran que las fases no son suficientes para cubrir con el objetivo de recuperar el testimonio del menor de edad de manera eficiente. 


\section{Capítulo 4. Discusión}

Como se observó en la fase de resultados en general los participantes calificaron de manera positiva la gran mayoría de las fases del protocolo, teniendo medias de puntuación mayores a 4.00 (5.00 es la mayor puntuación posible), por lo que se considera que en primera instancia el Protocolo para la toma de testimonio en niñas, niños y adolescentes por un equipo interdisciplinario es suficiente para la toma de testimonio de manera eficaz.

Las medias de puntuación más bajas se presentaron en la fase de "Rapport", la cual tuvo una media de calificación de 3.94, esta es una de las dos puntuaciones más bajas del instrumento; esto si indica que la fase es considerado como poco útil es importante tomar en cuenta que el cuestionario fue respondido en su mayoría por abogados, cuyos cargos son de jueces o magistrados, por lo que se infiere que al poseer una formación diferente, la cual busca establecer hechos y no conocer el estado psicológico de las personas, no están interesados en entablar relaciones de confianza con los menores de edad.

Lo anterior significa que el psicólogo, psiquiatra, trabajador social tienen una gran responsabilidad en socializar a los profesionales del derecho sobre la importancia de establecer el rapport con los menores de edad. También se puede considerar que la labor de la toma de testimonio es una tarea que el psicólogo debería ejercer en coordinación con los profesionales del derecho.

La segunda puntuación baja fue en el reactivo "Las fases sirven para cumplir con el objetivo", cuya media de puntuación también fue de 3.94, esto indica que si bien las fases del protocolo de manera individual fueron calificadas positivamente, en general los participantes consideran que aún pueden realizarse mejoras. Sería importante considerar explorar si los participantes consideran necesario aumentar alguna fase al protocolo para la toma de testimonio, pues en el instrumento no se preguntó la opinión de los participantes sobre este aspecto. 
Protocolo para el Testimonio en Niños y Adolescentes

\section{Referencias}

Anderson, J., Ellefson, J., Lashley, J., Lukas Miller, A., Olinger, S., Russell, A., Stauffer, J. y Weigman, J. (2006). The CornerHouse Forensic Interview Protocol: RATAC. Annual Meeting of The American Society of Criminology.

Andréu Abela, J. (s.f.). Las Técnicas de Análisis de Contenido: Una Revisión Actualizada.

Arias Galicia, L. (2012). Metodología de la Investigación (Septima ed.). México: Trillas.

Asamble General de las Naciones Unidas. (1990). Declaración sobre los Derechos del Niño.

Asamblea General de las Naciones Unidas. (1989). Convención de los Derechos del Niño.

Bauer, M. (2010). Classical Content Analysis: a Review. En M. Bauer, \& G. Gaskell, Qualitive Researching whith text, image and sound (págs. 131-151). Washington: SAGE.

Bembibre Serrano, J., \& Higueras Cortés, L. (2010). A vueltas con el error de Otelo: aplicación del modelo de control de fuentes a la credibilidad del testimonio y su afectaicón por la carga emocional. Psicothema, 125-130.

Benavides, J. A. (2007). El Arte del Interrogatorio Científico. México: Imágen Grafica Aplicada.

Cámara de Diputados del H. Congreso de la Unión. (19 de Agosto de 2010). Ley para la Protección de los Derechos de Niñas, Niños y Adolescentes. México, México.

Cantón, J., \& Cortés, M. R. (2006). Guía para la evaluación del Abuso Sexual Infantil. Madrid: Pirámide.

Colegio Oficial de Psicólogos. (s.f.). Perfiles Profesionales del Psicólogo. Psicología Jurídica.

Consejo Económico y Social de las Naciones Unidas. (10 de Agosto de 2005). Directrices sobre la Justicia en Asuntos Concernientes a los Niños Vícitmas y Testigos de Delitos. 
Contreras López, R. E. (s.f.). Principios Generales del Proceso Penal.

Damphouse, K. (S.F.). Voice Stress Analyisis: Only 15 percent of lies about drug use detected in field test. NIJ Journal, 259, 8-12.

Damphouse, K., Pointon, L., Upchurch, D., \& Moore, R. (2007). Assessing the Validity of Voice Stress Analysis Tools in a Jail Setting.

Espinosa, A. (2011). La Psicología del Testimonio. En G. Hernández, Psicología Jurídica Iberoamericana (págs. 197-228). Bógota: Manual Moderno.

Garrido, E., Massip, J., \& Herrero, C. (2007). Psicología Jurídica. España: Pearson Prentice Hall.

Garrido, E., Massip, J., \& Herrero, M. C. (2006). Psicología Jurídica. Madrid: Pearson.

Godoy Cervera, V., \& Dzib Aguilar, P. (2010). Psicología del Testimonio: Técnicas, instrumentos y procedimientos. En E. García López, Fundamentos de Psicología Jurídica y forense (págs. 493-521). México: OXFORD.

Gonzales, J., Muñoz, J., Sotoca, Á., \& Manzanero, A. (2013). Propuesta de Protocolo para la Conducción de la Prueba Preconstituida en Víctimas Especialmente Vulnerables. Papeles del Psicólogo, 227-237.

Governor's Task Force on Child Abuse on Neglect and Department of Human Services (2011). Forensic Interview Protocol. 3a Ed.

Heinz, O. (2000). El Dictamen sobre la Credibilidad de las Declaraciones de los Testigos. Anuario de Psicología Juridica, 11-23.

Hernández Fernández, E., \& Alonso Quecuty, D. M. (S.F.). La detección de la mentira: Perspectiva científica vs legal.

Hernández Sampieri, R., Fernández Collado, C., \& Baptista Lucio, P. (2010). Metodología de la Investigación (Quinta Edición ed.). Perú: McGraw-Hill. 
Hopkins, S., Benincasa, D., Rattley, R., \& Grieco, J. (2005). Evaluation of Voice Stress Analysis Technology. 38th Hawaii International Conference of System Sciences.

Howitt, D. (2009). Introduction to Forensic and Criminal Psychology (3a ed.). Inglaterra: Pearson Education.

Iacond, W. G., \& Patrick, C. J. (2006). Polygraph ("Lies detector") Testing: Current Status and Emerging Trends. En I. B. Weiner, \& A. K. Hess, The handbook of Forensic Psychology (págs. 552-584). USA: John Wile \& Sons, Inc.

Ibabe Erostarbe, I. (2000). Psicología del Testimonio. Itxaropena: Erein.

Ibañez Peinado, J. (2008). Aspectos Psicológicos del Testimonio en la Investigación Criminal. Tesis no publicada. Madrid.

Loftus, E., Greene, E., \& Doyle, J. (1994). La Psicología del Testimonio del Testigo Presencial. En D. C. Raskin, Metodos Psicologicos de la Investigación y Pruebas Criminales (págs. 24-49). Bilbao: Desclée de Brouwer.

Manzanero, A. (2008). Psicología del Testimonio. Una Aplicación de los Estudios de Memoria. Madrid: Editorial Piramide.

Manzanero, A. (2010). Memoria de Testigos: Obtención y Valoración de la Prueba Testifical. España: Piramida.

Manzanero, A., \& Diges, M. (1994). Analisis de la Credibilidad de Recuerdos Percibidos e Imaginados. Apuntes de Psicología, 81-92.

Manzanero, A., \& González, J. (2013). Avances en Psicología del Testimonio. Santiago de Chile: Ediciones Jurídicas de Santiago.

Masip, J., Sporer, S., Garrido, E., \& Herrero, C. (2005). The detection of deception with the reality monitoring approach: a review of the empirical evidence. Psychology, Crime \& Law, 11, 99-122.

Muñoz, J. M., Manzanero, A. L., Alcazar, M. A., González, J. L., Pérez, M. L., \& Yela, M. (2011). Psicología Jurídica en España: Delimitación Conceptual, Campos de 
Investigación e Intervención y Propuesta Formativa dentro de la Enseñanza Oficial. Anuario de Psicología Jurídica, 21, 3-14.

Pozo Huerta, C. (2005). El testimonio en la práctica jurídica. En M. A. Soria Verde, Manual de Psicología Jurídica e Investigación Criminal (págs. 97-113). España: Ediciones Piramide.

Rosenfeld, J. P. (2002). Event-related potentials in the detection of deception, malingering, and false memories. En M. Kleiner, Handbook of polygraph testing (págs. 265286). Nueva York: Academic Press.

Sáiz Roca, D., Baqués Cardona, J., \& Sáiz Roca, M. (2006). Psicología del Testigo: Conceptos Fundamentales. En M. A. Soria Verde, \& D. Sáiz Roca, Psicología Criminal (págs. 123-187). España: Pearson Prentice-Hall.

Secretaría de Seguridad Pública. (2005). Modelo Especializado para la Toma de Declaraciones Infantiles. ¿Cómo obtener información sin revictimizar al niño? México: Oficina de la Defensoría de los Derechos de la Infancia A.C.

Suprema Corte de Justicia de la Nación. (2014). Protocolo Iberoamericano de Actuación Judicial para Mejorar el Acceso a la Justicia de Personas con Discapacidad, Migrantes, Niñas, Niños, Adolescentes, Comunidades y Pueblos Indigenas. México.

Tulving, E., \& Thompson, D. (1973). Encodign specifity and retrieval processes in episodic memory. Psychological Review, 352-373.

Vázquez Mesquita, B. (2007). Manual de Psicología Forense. España: Editorial Síntesis.

Vrij, A. (2000). Detecting lies and deceit: the psychology of lying and the implications for professional practice. Chichester: John Wiley \& Sons.

Weiner, I., \& Hess, A. (2006). The Handbook of Forensic Psychology. Nueva Jersey: Wiley \& Sons.

Xianfeng, L. (2005). Voice Stress Analisys: Detection of Deception. University of sheffield. 
Protocolo para el Testimonio en Niños y Adolescentes

Yucatán, H. C. (08 de Juni0 de 2011). Código Procesal Penal para el Estado de Yucatán. Mérida, Yucatán, México. 


\section{Apéndice A}

\section{Protocolo para la toma del testimonio interdisciplinario en niñas, niños y adolescentes}

\section{Presentación}

El presente protocolo busca brindar una guía valida y científica para guiar el trabajo de los diferentes profesionales o actores inmersos en un proceso legal, cuando tengan que recuperar el testimonio de un menor. Es importante mencionar que la finalidad del protocolo es brindar recomendaciones de pasos o fases a seguir, y no ser una herramienta rígida y estricta que deba realizarse siempre al pie de la letra, los profesionales que usen este documento podrán adecuar los pasos sugeridos a las necesidades particulares de cada situación (características del niño, características del caso, infraestructura etc.).

Dicho protocolo se realizó fundamentado en la búsqueda de proteger el interés superior del niño acorde a los tratados internacionales suscritos por México, la Constitución Política de los Estados Unidos Mexicanos, las leyes federales y locales del estado de Yucatán y en las aportaciones de la psicología del testimonio para recuperar en testimonio de la manera más confiable y precisa posible; de igual manera se incorporaron las prácticas realizadas en otros países y otros protocolo o guías de entrevista para la recuperación del testimonio en menores de edad.

\section{Sustento teórico}

El estudio del testimonio es una temática que ha sido estudiada durante mucho tiempo por diferentes autores, lo que propició a que se desarrolle el área de la psicología conocida como Psicología del Testimonio o del Testigo. Para Saíz, Baqués y Saíz (2005) (como se citó en Espinosa, 2011) la Psicología del Testimonio es una subespecialidad de la psicología jurídica y que denota su campo de aplicación dentro de la psicología forense.

Ya en 1982, Hosch y Cooper (Ibañez Peinado, 2008) mencionaban que el principio común que guía la investigación en el campo de la psicología del testimonio es el convencimiento de que el testimonio de las víctimas y/o de los testigos que sufren o 
presencian un determinado hecho, el cual es delictivo, es la base fundamental, y a veces única, de las investigaciones de esclarecimiento de los delitos.

En tiempos modernos la investigación en Psicología del Testimonio tiene dos claras aplicaciones profesionales: por un lado, para el psicólogo criminalista (aplicaciones de técnicas de entrevista para el interrogatorio policial, elaboración de retratos robots o reconocimiento de sospechosos) y por otro, para el psicólogo forense (facilitar la toma de declaraciones de las partes y asesorar a los tribunales para un mejor valoración del prueba testifical) (Muñoz, et al., 2011). Y por otro lado, la psicología del testimonio se ha centrado en dos claros vectores de estudios: una es la exactitud y la otra, la credibilidad (Saíz Roca, et al, 2006).

El estudio de la exactitud o validez se preocupa del análisis de los factores que pueden incidir sobre la fidelidad o exactitud entre lo que realmente ocurrió y lo que el testigo relata. En esta aproximación se supone que el testigo es honesto, pero que su memoria puede fallar, por lo que se analiza la exactitud e inexactitud del testigo. Por otra parte el estudio de la credibilidad analiza la continuidad entre la verdad y la falsedad del testimonio, incluye los testimonios de testigos honestos que por razones independientes de su voluntad faltan a la verdad de su recuerdo, así como las versiones falsas de un testigo que tiene la intención de mentir (Pozo Huerta, 2005).

Exactitud del testimonio. Este elemento del testimonio está fuertemente relacionado con la exactitud de la memoria, la cual se entiende como la reproducción de forma correcta y compleja de los hechos originales. Existen ciertas circunstancias que pueden afectar la memoria de las personas volviéndola imprecisa o inexacta. Wells hizo una de las primeras clasificaciones de las variables que afectan la exactitud de la memoria: variables a estimar de las circunstancias en las que se producen los sucesos y variables propias del sistema para tomar declaración a los testigos (Pozo Huerta, 2005).

Las variables a estimar se pueden dividir en dos categorías, primero los factores de la situación, los cuales son aspectos como las condiciones ambientales en las que se produjo el suceso (distancia, oscuridad, niebla), el tipo de suceso (violación, accidente, robo, etc.) la duración del suceso, grado de violencia del mismo, etc., la segunda categoría, 
factores de los testigos, alude a las características de cada testigo, como el sexo, edad, estrés, expectativas, perjuicios, valores y entrenamiento. En cambio las variables del sistema se refieren a aquellos aspectos que pueden ser manipulados y optimizados o, al contrario, influir negativamente en el recuerdo de los hechos o la identificación del sospechoso. Entre estas variables se encuentran las instrucciones dadas a los testigos, el intervalo de tiempo entre la denuncia y la declaración, el tipo de preguntas y el orden en que se formulan, la composición de las ruedas de identificación, la información post-suceso que el sujeto pueda recibir por parte de algún funcionario de la policía (Pozo Huerta, 2005).

Manzanero (2010) categoriza estas variables de acuerdo a los factores que afectan la huella de la memoria, así están divididas en:

b) Factores que afectan la fase de codificación de la memoria, b) factores que afectan la fase de retención de la información y c) factores que afectan la recuperación de la información.

A continuación se presentan las principales variables a estimar y del sistema que pueden afectar el testimonio de las personas.

\section{Variables a estimar.}

Condiciones de iluminación. Los cambios bruscos en las condiciones de iluminación pueden causar un pobre sensibilidad visual. Los testigos presenciales que han sido sometidos a cambios bruscos en las condiciones de iluminación durante el suceso pueden tener dificultades para percibir adecuadamente los hechos (Pozo Huerta, 2005).

Duración del suceso. El tiempo de exposición al suceso es un factor importante para in mejor rendimiento de la memoria, a mayor duración del suceso, este podrá ser mejor percibido y codificado (Pozo Huerta, 2005)

Violencia del suceso. Algunos estudios sugieren que la violencia de un suceso puede dificultar la capacidad de un sujeto para percibirlo y recordarlo. Otros estudios aseveran que la violencia de un suceso puede distorsionar las percepciones ocurridas desde el inicio 
de la violencia. Los hechos emotivos parecen provocar el efecto de que la gente se preocupe por sí misma, se inquiete y se distraiga más. Easterbook a finales de los cincuenta destaco los efectos de las emociones en la selectividad de la atención, señalando que un suceso altamente emotivo está acompañado de una disminución de la atención, debido a lo cual tienden a percibirse menos detalles, a pesar de que el tema principal de suceso y los detalles importantes pueden ser percibidos y recordados (Pozo Huerta, 2005)

Estrés y miedo. La ley de Yerkes-Dodson sugiere que el nivel de rendimiento aumentará a veces y disminuirá en otras ocasiones por los aumentos de estrés. De acuerdo a esta ley existe un nivel óptimo de estrés en que el rendimiento de un sujeto es mejor. En el ámbito forense existen opiniones divididas sobre los efectos del estrés en el testimonio. Deffenbacher (1983) revisó un total de 21 investigaciones sobre el estrés y la memoria del testigo, 11 de estos estudios sugieren que niveles de estrés altos disminuyen la precisión del testigo, los otros 10 señalan que la activación alta no disminuye la precisión del recuerdo. Deffenbacher argumentó que los primeros estudios trataron con niveles de activación más parecidos a los que ocurren en homicidios, asaltos, robos y violaciones (Pozo Huerta, 2005).

Focalización en el arma. Un efecto del estrés consiste en que se reduce la atención, de tal forma que las personas se concentran en ciertas características de su entorno y, consecuentemente, prestan menos atención a otras características. Este fenómeno de focalización en el arma alude a la concentración de la atención del testigo en un arma y a la resultante reducción en la habilidad para recordar otros detalles del crimen (Pozo Huerta, 2005).

Estrés crónico. Alude a un estado de ansiedad causada por ciertos sucesos vitales estresantes. El estrés crónico puede causar preocupación de modo que los individuos no prestan atención a los estímulos de su entorno, pudiendo perder información importante y necesaria para un recuerdo preciso (Pozo Huerta, 2005).

Expectativas y estereotipos. La memoria de los testigos está influenciada por los conocimientos y experiencias adquiridas. Se ha comprobado que si un testigo no puede precisar algún tipo de información, recurre a los estereotipos. Los sujetos pueden recurrir a 
los estereotipos en situaciones donde la percepción del suceso ha sido imperfecta y sobre todo si, mientras declaran, son presionados para dar información (Pozo Huerta, 2005).

Edad. En general los niños ofrecen una información más limitada que los adultos, pero lo que dicen no es menos exacto. También se cree que los niños más pequeños son mas sugestionables, en varios estudios se ha visto que los niños menores de tres años son más sugestionables que los adultos, sin embargo en investigaciones con niños mayores de cinco años no se han encontrado diferencias en la sugestionabilidad de los niños y los adultos. En estudios con personas de la tercera edad algunos estudios concluyen que los testigos mayores no son tan capaces como los jóvenes adultos de describir o identificar a la gente que han visto antes. Por lo tanto hay que tratar el testimonio de las personas mayores con cautela, lo que no implica desvalorizar su testimonio (Pozo Huerta, 2005).

Sexo: Con respecto a esta variable las investigaciones muestran que en general el sexo de los testigos no afecta a su memoria (Pozo Huerta, 2005).

Entrenamiento. Esta variable se refiere al grado en que una persona en virtud de su empleo, experiencia o entrenamiento, puede ser mejor testigo que otra. El entrenamiento puede aumentar la probabilidad de que un testigo haga un esfuerzo deliberado durante el proceso para prestar atención a los detalles y tratar de recordarlos. En una investigación realizada por Loftus en 1981 se comparó a detectives de delitos de incendios con estudiantes en cuanto a su habilidad para recordar detalles de una película que mostraba un incendio en un hospital (Pozo Huerta, 2005).

\section{Variables del sistema.}

Olvido. Son muy conocidas las investigaciones de Ebbinghaus sobre el olvido y como sus resultados dieron origen a la llamada "curva del olvido", la cual muestra que los sujetos olvidan una gran parte de la nueva información poco después de aprenderla y posteriormente el olvido se va haciendo más gradual. Aplicado al testimonio es obvio que en cuanto más tiempo pase entre el hecho presenciado y la primera declaración, más deterioro existirá en el recuerdo de los sucesos, pero no solo existe el riesgo de deterioro del recuerdo sino el de su distorsión o transformación (Pozo Huerta, 2005). 
Información postsuceso. Durante la retención del evento, las experiencias posteriores al suceso pueden afectar a la memoria del suceso original, alternando o trasformando el recuerdo de este. Varias investigaciones han comprobado que las presuposiciones son capaces de transformar el recuerdo de una persona, así como también de complementarlo. Por lo tanto es posible introducir información falsa en el recuerdo de una persona y después la persona relata esa información como si realmente hubiese ocurrido (Pozo Huerta, 2005).

Métodos de interrogación. Numerosas investigaciones dan cuenta que el tipo de preguntas realizadas en los interrogatorios a testigos pueden inducir el recuerdo de cosas que nunca has estado presentes (Loftus, Greene, \& Doyle, 1994). Para reconstruir el recuerdo del testigo de manera eficaz el entrevistador debe conocer las formas en que la evocación del recuerdo puede verse afectada por distintos métodos de elicitación. Los investigadores han sugerido que se obtendrían buenos resultados con una estrategia de interrogatorio que primero permita una narración libre para después hacer preguntas específicas, teniendo mucho cuidado con la forma en que se realiza la pregunta (evitar preguntas sugestivas o inductoras) (Pozo Huerta, 2005).

Recuperación múltiple. La cantidad de veces que un testigo ha tenido que recuperar un suceso, es uno de los factores importantes de distorsión que se deben de tener en cuenta al analizar la exactitud del recuerdo del testigo. Los individuos involucrados en un proceso penal suelen narrar varias veces lo que han presenciado; en el caso de abuso sexual a menores, estos pueden ser preguntados alrededor de unas 30 o 50 veces por aproximadamente nueve personas diferentes (padres, profesores, médicos, trabajadores sociales, abogados, jueces, policías, psicólogos, etc.) y no todos procuran hacer preguntas sin contaminar el recuerdo (Cantón \& Cortés, 2006).

Cada vez que se recuerda un suceso la huella mnémica que lo representa se reconstruye, lo que implica que con cada recuperación los recuerdos se van transformando mediante la incorporación de nuevos datos y la reinterpretación de los ya existentes (Cantón \& Cortés, 2006). Esto quiere decir que a mayor cantidad de declaraciones que la persona de sobre el suceso habrá una mayor diferencia con respecto a la primera declaración hecha. 
Tiempo transcurrido desde el suceso. Manzanero y Diges (1994), encontraron que la preparación juega un papel determinante en la calidad del recuerdo, mientras más tiempo pase entre el suceso y la declaración la persona puede construir el recuerdo, lo que dificulta la capacidad de los evaluadores de determinar correctamente si un recuerdo es real o imaginario.

\section{Descripción del protocolo.}

Este protocolo está dividido en las siguientes fases o pasos que se recomienda seguir:

1. Preparación del espacio físico,

2. Preparación de equipo de video,

3. Preparación de los tutores del niño, niña o adolescente,

4. Preparación del niño, niña o adolescente,

5. Evaluación del estado del niño, niña o adolescente,

6. Preparación del cuestionario,

7. Toma del testimonio,

8. Resolución de dudas y

9. Valoración de la exactitud del testimonio.

\section{Fases del protocolo.}

\section{Preparación del cuestionario por parte del equipo interdisciplinario}

Acorde al artículo 249 del Código Procesal Penal para el Estado de Yucatán, en esta fase el equipo interdisciplinario, el cual estará conformado por los profesionales relacionados directamente con el caso (médicos forenses, químicos forenses, criminalistas, abogados, agentes ministeriales, jueces, abogado defensor, psicólogo, etc.) deben elaborar una lista de preguntas que sean pertinentes y necesarias.

Las preguntas que integran este cuestionario deben ser las necesarias para que cada uno de los profesionales obtenga la información necesaria, serán los psicólogos (as) forenses los que deban valorar que las preguntas no atenten contra la integridad del menor y que esta adecuada a la capacidad cognitiva y el lenguaje del menor. 
El objetivo de preparar un solo cuestionario es salvaguardar la integridad del menor y evitar la sobre-victimización, es decir, procesos que vulneren la estabilidad emocional del menor y atenten contra el interés superior del mismo.

\section{Adecuación del espacio físico}

La distribución y decoración del espacio donde se realizará la toma de la declaración es de gran importancia, debe ser un lugar agradable para el menor, en el cual se sienta cómodo y al que no presente estímulos que puedan distraer al menor.

La distribución del espacio estará sujeta a la disponibilidad de lugares idóneos por parte de las instituciones de justicia, se recomienda el uso de cámaras de Gesell, cubículos especializados para tomar la declaración o usar circuito cerrado de televisión, en caso de no contar con estos espacios se debe buscar adecuar las instalaciones con las que se cuenten lo mejor posible.

Independiente a las condiciones específicas de las que el equipo interdisciplinario cuente se debe procurar siempre cuidar los siguientes aspectos (Secretaría de Seguridad Pública, 2012):

a) Contar con un espacio destinado solamente a la entrevista con el menor, no se debe entrevistar en pasillos o espacios donde se encuentren personas ajenas al caso, por ejemplo salas de espera.

b) Que el espacio esté libre de estímulos distractores, con la menor cantidad de ruido.

c) Contar con asientos cómodos, y que permitan que él o la menor y los o las entrevistadoras estén a la misma altura.

d) Se recomienda que no exista una barrera física entre él o la menor y los o las entrevistadoras.

e) Aunque se pueden usar medios lúdicos (crayolas, colores, muñecos, etc.) si el menor muestra resistencia para hablar, estos no deben estar a la vista del menor al iniciar el proceso de toma de testimonio.

f) Preparar la ubicación del equipo de video para grabar la totalidad de las sesiones. 


\section{Preparación de los tutores del niño, niña o adolecente.}

Es importante antes de comenzar con el proceso de toma de testimonio que a los tutores del menor se les brinde la información pertinente con respecto al procedimiento, la finalidad del procedimiento, el tiempo que puede durar, la información que se busca obtener del menor, las personas que estarán presentes, los derechos a los que él menor posee, así como las medidas de protección que se tomarán para cuidar el bienestar de la niña, niño o adolescente. Se recomienda que la persona que realice esta acción sea el elemento del ministerio público junto a un psicólogo que realice el acompañante del menor.

Se debe mencionar a los tutores que en todo momento se protegerá la integridad del menor, pero que es un proceso necesario para la investigación realizar la entrevista para recuperar el testimonio.

\section{Preparación del niño, niña o adolescente.}

Antes de iniciar con la toma de la declaración del menor se debe procurar explicar al menor la finalidad de tomar su declaración y la importancia de realizar dicha acción, esta explicación debe estar acorde a la edad y capacidad cognitiva del menor. También se debe aclarar con el menor el número de personas que estarán presentes, el tipo de preguntas que se harán, el tiempo aproximado que pueda durar la diligencia, etc. También se recomienda que el agente ministerial junto al psicólogo acompañante realice esta acción.

La niña, niño o adolescente que testifique debe ser acompañado por un profesional que lo sensibilice sobre el procedimiento en el cual participará. Este profesional debe ser ajeno al equipo interdisciplinario que recuperará el testimonio para cuidar que la recuperación del testimonio sea objetiva y confiable.

Es importante no hacer promesas al menor y que su participación es muy importante y que se agradece su ayuda, aunque más adelante en el protocolo se mencionan las instrucciones que se darán al menor al realizar la entrevista, es importante que antes del 
proceso de entrevista, el menor pueda familiarizarse con las personas que lo entrevistarán y los procedimientos que se realizarán.

\section{Preparación de equipo de video.}

Siguiendo las recomendaciones de distintos protocolos (protocolo de entrevista forense de Michigan, Protocolo para el acceso a la justicia para juzgadores que trabajan con niñas, niños y adolescentes, etc.) se debe grabar en audio y video todas las sesiones que se realicen con los menores. Se recomienda que se designe a una persona para la supervisión del equipo de grabación. El equipo de grabación debe estar colocado de tal manera que todas las personas presentes en el momento de la entrevista estén a la vista y que se escuche claramente la voz de todas las personas que participarán. Es preferible que antes de realizar la entrevista se pruebe que el equipo funciona correctamente y que el espacio tiene el espacio adecuado para que la cámara de video capture toda la habitación.

\section{Evaluación del estado del niño y adolescente}

Esta primera fase del proceso de toma de testimonio involucra conocer las características psicológicas, sociales, biológicas del menor con la finalidad de evaluar la capacidad del menor para testificar y que si existen elementos que pueden afectar la validez del testimonio.

\section{Toma de testimonio/entrevista}

Se recomienda que el testimonio sea recogido por dos psicólogos (el sexo de ambos psicólogos dependerá de las circunstancias específicas del caso, aunque se recomienda que sea un psicólogo de cada sexo) un psicólogo(a) encargado de la toma del testimonio y otro psicólogo (a) que funja como apoyo técnico (proceso en la corte de Barcelona).

- Ambos psicólogas(os) encargados de la toma de testimonio, recogen las preguntas de ambas partes (agente del ministerio y abogado defensor) que necesiten hacer. 
- Existen en el área forense técnicas e instrumentos validos científicamente destinados a recuperar el testimonio de un menor como los son. El "Protocolo de Entrevista Forense de Michigan" o la "Entrevista Cognitiva" en sus diferentes versiones (tradicional, mejorada o modificada). Tomando en cuenta dichas entrevistas se recomienda que el testimonio siga las siguientes fases:

1. Presentarse ante el menor y crear Rapport: se recomienda que los o las entrevistadoras se presenten ante el menor dando sus nombres de pila y la función que realizan, por ejemplo: "Hola, mi nombre es___ y yo trabajo aquí, lo que hago es escuchar con niñas (os) como tú, y hoy voy a platicar contigo". No es necesario dar demasiada información a los menores acerca del procedimiento legal, sin embargo si es recomendable mencionar la menor que la entrevista será grabada todo el tiempo, así como el hecho de que habrá personas que estén escuchando la entrevista (entre ellos sus tutores).

Durante esta fase, es un buen momento para los/las entrevistadoras recopilar información acerca de las habilidades cognitivas y de lenguaje del menor.

3. Establecer reglas: en diferentes protocolos (protocolo de entrevista forense, protocolo de actuación para quienes imparten justicia en casos que involucren a niñas, niños y adolescentes) se contempla que antes de comenzar con la entrevista se debe plantear las reglas que se seguirán durante la entrevista a la niña, niño o adolescente, se recomienda establecer las siguientes reglas:

\section{- No adivinar:}

- Dime si no entiendes:

- Corrígeme:

\section{- Di la verdad:}

Verdad/Mentira: Antes de comenzar con la entrevista es necesario valorar si el menor de edad puede discernir entre una verdad y una mentira, para esto se puede pedir al menor que explique la diferencia entre ambos conceptos. En caso de que el menor de edad no pueda, 
porque es demasiado pequeño por ejemplo, el entrevistador pondrá ejemplos al niño o niña, se recomienda hacerlo de la siguiente manera:

Entrevistador/a: ¿Sabes la diferencia entre la verdad y la mentira? Por ejemplo yo tengo una camisa blanca (verdad) ¿eso es verdad o mentira? - esperar respuesta del menor - Muy bien eso es verdad por qué tengo puesto una camisa de color blanco.

Si el niño responde correctamente el entrevistador dará un ejemplo que sea mentira. En caso de que responda incorrectamente dar otro ejemplo para corroborar si el menor de edad comprende el concepto o simplemente el ejemplo fue muy complicado para él.

Entrevistador/a: Muy bien, ahora dime si lo que te voy a decir es verdad o mentira, Yo no tengo los zapatos puestos, ¿Eso es verdad o mentira? (mentira) - Esperar respuesta del menor de edad- Correcto, eso es una mentira por qué yo si tengo puesto zapatos.

Si el niño responde correctamente el entrevistador podrá proseguir con la entrevista, en caso contrario se recomienda tener reservas sobre la información proporcionada por el menor de edad.

4. Realizar una breve práctica: En esta apartado se pedirá al menor que relate algún acontecimiento de un día común en su vida, como ir a la escuela o lo que hizo el último fin de semana. Esta fase sirve para valorar la capacidad del menor de edad para brindar su testimonio y que su memoria este intacta.

Entrevistador: Muy bien ahora me quiero que me platiques sobre lo que haces en un día normal, por ejemplo cuando vas a clases, cuéntame todo lo que recuerdes desde que te levantas hasta que te vas a dormir.

5. Mencionar el tema de la entrevista: Antes de comenzar la entrevista el entrevistador debe poder dirigir al menor de edad al tema que del que se trata la entrevista, debe cuidar no dirigir ni sugestionar al menor. Puede hacer preguntas como: ¿Sabes por qué te trajeron a hablar conmigo?, ¿Dime por qué crees que viniste a hablar conmigo? 
6. Situar al menor en el contexto: basado en la entrevista cognitiva, se recomienda pedir al menor que recuerde como se encontraba en el momento de lo sucedido. Se pregunta al menor: ¿recuerda donde te encontrabas?, ¿Cómo te sentías?, ¿Qué estabas haciendo en ese momento?, ¿Sentiste algún olor o escuchaste algún sonido?

7. Narrativa libre o recuerdo libre: pedir al menor que relate el suceso de principio a fin, pidiendo que incluya todos los detalles que recuerde incluyendo detalles insignificantes o irrelevantes.

8. Interrogatorio y aclaración: se cuestionará al menor sobre aquellos detalles o información que no quedo del todo clara, es importante no preguntas sugestivas, dirigidas, preguntas dobles y cuidar el uso de las preguntas cerradas.

- Preguntas específicas: el psicólogo que funge como asistente preguntará a las partes (agente del ministerio y abogado defensor) si hay información que aún no quede clara o si falta explorar alguna temática. En esta fase también es necesario valorar la pertinencia de las preguntas de acuerdo a las características del menor y valoran la mejor manera de formular dichas preguntas, cuidando de no cambiar el sentido de los cuestionamientos.

9. Reformulación de preguntas por parte del equipo interdisciplinario: En esta fase los entrevistadores preguntarán al resto del equipo interdisciplinario si desean hacer más preguntas, siempre que estás aporten información nueva y relevante que no haya sido explorada anteriormente. Los entrevistadores valorarán si es pertinente realizar las nuevas preguntas y la mejor manera para adecuarlas a la edad y capacidades del menor de edad.

10. Cerrar la entrevista: diversos protocolo de entrevista sugieren que el cierre con el menor debe ser de tal forma que no se termine de golpe la entrevista, se puede cambiar el tema de la entrevista preguntando al menor sobre temas poco importantes, como lo que hará el día de mañana, o que hará cuando llegué a casa. 


\title{
Apéndice B
}

\section{Cuestionario para evaluar el protocolo del testimonio \\ PROTOCOLO PARA LA RECUPERACIÓN DEL PRIMER TESTIMONIO POR UN EQUIPO INTERDISCIPLINARIO}

\author{
Fundamentación
}

\section{Justificación}

En el año 2008 se da en México un cambio en el sistema de procuración de justicia, este cambio busca que el sistema de procuración de justicia en México pase de ser un sistema de justicia inquisitivo donde la contradicción y la publicidad del proceso están limitados a ser un sistema donde se exista el principio de contradicción y publicidad (Contreras López, s.f.).

La creación de este protocolo se sustenta en el artículo 249 primer párrafo, del Código Procesal Penal para el Estado de Yucatán, el cual señala que: "Cuando deban realizarse diferentes peritajes a personas agredidas sexualmente, incapaces o menores de edad, deberá integrarse, en un plazo breve, un equipo interdisciplinario, con el fin de concentrar en un misma sesión las entrevistas que requiera la víctima"; el segundo párrafo de dicho artículo también menciona que: "Antes de la entrevista, el equipo de profesionales deberá elaborar un protocolo y designará, cuando lo estime conveniente, a uno de sus miembros para que se encargue de plantear las preguntas".

\section{Objetivo}

Convenir un protocolo interdisciplinario para sistematizar la toma del testimonio haciendo más eficiente el proceso al igual que evitar la sobre-victimización en menores de edad. 


\section{Datos generales}

Edad:

Sexo:

Profesión:

Grado académico terminado:

Ocupación:

Instrucciones: A continuación se presentan y describen sintéticamente las diferentes fases que conforman el protocolo, marque la casilla que usted considera responde el grado en que cada fase es útil para alcanzar el objetivo del protocolo. Use la las siguientes opciones para responder.

$\begin{array}{lllllllll}\text { 1. Nada útil } & \text { 2. } & \text { Poco útil } & \text { 3. Útil } & \text { 4. } & \text { Muy útil } & \text { 5. } & \text { Totalmente útil }\end{array}$

Debajo de cada fase encontrará una sección para que usted escriba sus comentarios y sugerencias.

\section{FASES DEL PROTOCOLO}

\section{Acreditación del delito}

\section{FASE 1}

En esta fase los profesionales adscritos al órgano de procuración de justicia (fiscalías, ministerio público, procuradurías) deben buscar delimitar los criterios necesarios para la acreditación del cuerpo del delito con la información proporcionada por los denunciantes (menores de edad y representantes legales), para lo cual deberán establecer en conjunto, de acuerdo al área profesional a la que pertenezcan, las preguntas necesarias para recoger la información del testimonio de los menores de edad que sirva para tipificar el delito (Art. 249 del Código Procesal Penal para el Estado de Yucatán):

a) Ministerio público: reunir los datos necesarios para que el juez de control determine si existe delito que investigar.

b) Médico forense: recoger la información necesaria para establecer la mecánica de las lesiones, en caso de que existan.

c) Químico forense: reunir los datos que le permitan establecer la presencia u origen de las sustancias que analizará.

Psicólogo forense/trabajador social: su labor consiste en adecuar las preguntas formuladas por los demás miembros del equipo multidisciplinario a las características y capacidades del testigo al igual que evitar que se sobre-victimice al menor de edad.

\section{Comentarios y sugerencias}




\begin{tabular}{|c|l|l|l|l|l|}
\hline FASE 2 & & & & \\
\hline Preparación del menor de edad y de los representantes & & & & & \\
legales & & & & \\
\hline
\end{tabular}

Se debe brindar al representante legal del menor de edad así como al menor de edad la lo pertinente con respecto al procedimiento, la finalidad del procedimiento, el tiempo que puede durar, la información que se busca obtener del menor, las personas que estarán presentes, los derechos a los que él menor posee, así como las medidas de protección que se tomarán para cuidar el bienestar de la niña, niño o adolescente.

Dependiendo de la edad del menor, puede ser útil que el menor conozca los espacios, así como a las personas que participarán en el proceso, para reducir su ansiedad ante el proceso.

\section{Comentarios y sugerencias}

FASE 3

\section{Adecuación del lugar de la entrevista}

El espacio donde se realice la entrevista debe ser un lugar agradable para el menor, en el cual se sienta cómodo y al que no presente estímulos que puedan distraer al menor.

Se recomienda el uso de cámaras Gesell, cubículos especializados para la toma de la declaración, uso de circuito cerrado de televisión. Se recomienda que dentro del espacio de entrevista solo estén presentes los entrevistadores(as) todas las demás personas (peritos, abogados, representantes del menor, ministerio público) estarán fuera, aunque deben ver y escuchar el proceso de entrevista.

\section{Comentarios y sugerencias}

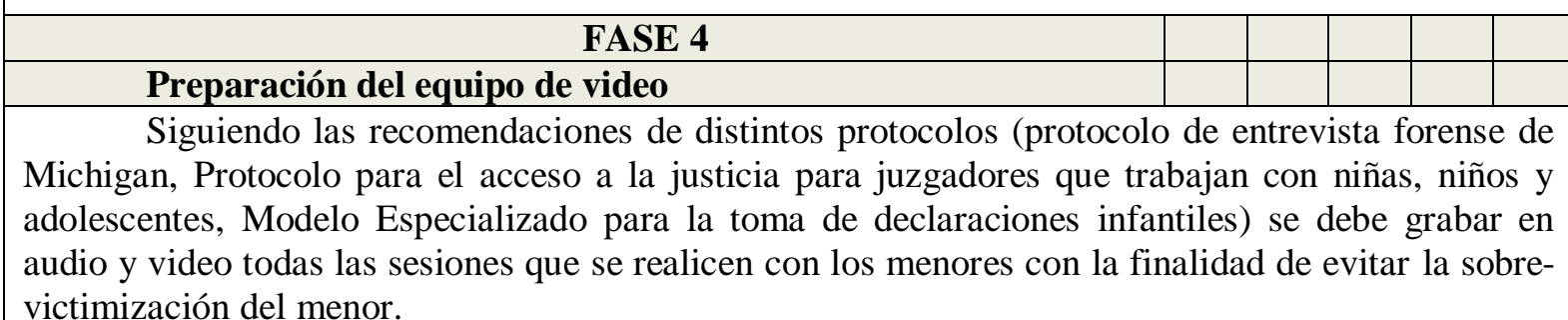
victimización del menor.

\section{Comentarios y sugerencias}

\section{FASE 5}

\section{específicas (Cribado)}

\section{Valoración general para tomar decisiones a evaluaciones más}

Involucra conocer las características psicológicas, sociales, biológicas del menor con la finalidad de evaluar la capacidad del menor para testificar y si existen síntomas de posibles trastornos mentales o de memoria que puedan afectar la validez del testimonio. Esta fase no corresponde a una evaluación psicológica como tal, sino como una breve exploración para determinar si es necesario realizar evaluaciones específicas.

\section{Comentarios y sugerencias}




\section{FASE 6}

\section{Toma del testimonio}

\subsection{Rapport}

Presentación de los entrevistadoras(es) ante el menor de edad y la función que realizan (se recomienda usar dos entrevistadores(as), uno que funge como entrevistador principal y otro como co-entrevistador, tomará notas y estará en contacto con el equipo multidisciplinario) durante esta fase, es un buen momento para los/las entrevistadores(as) recopilar información acerca de las habilidades cognitivas y de lenguaje del menor.

\section{Comentarios y sugerencias}

\subsection{Establecimiento de reglas}

Diferentes protocolos (protocolo de entrevista forense, protocolo de actuación para quienes imparten justicia en casos que involucren a niñas, niños y adolescentes, ) contemplan plantear las reglas que se seguirán durante la entrevista a la niña, niño o adolescente:

a) El menor de edad no debe adivinar, solo decir lo que sabe,

b) Puede informar al entrevistador si no entiende algo,

c) Puede corregir al entrevistador si se equívoca sobre algún dato del testimonio, y El menor siempre debe responder con la verdad.

\section{Comentarios y sugerencias}

\subsection{Verdad/mentira}

\begin{tabular}{|l|l|l|l|l|}
\hline & & & & \\
\hline & & & & \\
\hline
\end{tabular}

Se debe establecer que el menor de edad es capaz de comprender entre lo que es considerado como verdad y lo que es considerado como mentira.

\section{Comentarios y sugerencias}

\subsection{Práctica}

\begin{tabular}{|l|l|l|l|l|}
\hline & & & & \\
\hline & & & & \\
\hline
\end{tabular}

Antes de comenzar con la toma del testimonio se puede pedir al menor que nos relate la rutina que sigue en un día común, este ejercicio es para que asegurar que el menor de edad ha comprendido las instrucciones y conocer la manera en que el menor se expresa normalmente.

\section{Comentarios y sugerencias}

\subsection{Narrativa libre}

Se pide al menor de edad que relate lo que le sucedió de principio a fin, pidiendo que incluya todos los detalles que recuerde incluyendo detalles insignificantes o irrelevantes, en esta parte del procedimiento los entrevistadores no deben interrumpir o hacer preguntas al menor, aunque si pueden usar expresiones para alentarlo a que continúe con su declaración.

\section{Comentarios y sugerencias}




\subsection{Clarificación de dudas}

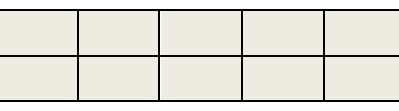

Se cuestionará al menor sobre aquellos detalles o información que no quedo del todo clara, es importante no preguntas sugestivas, dirigidas, preguntas dobles y cuidar el uso de las preguntas cerradas.

\section{Comentarios y sugerencias}

\section{multidisciplinario}

6.7. Reformulación de preguntas del equipo

En esta parte del proceso el/la co-entrevistador(a) saldrá del espacio de entrevista para preguntar a los integrantes del equipo multidisciplinario si necesitan más información, el/la coentrevistador(a) determina si las preguntas son necesarias y las adecua a las características del menor de edad entrevistado.

\section{Comentarios y sugerencias}

\subsection{Cierre}

Es necesario que al terminar la entrevista con el menor no sea de golpe, se puede cambiar el tema de la entrevista preguntando al menor sobre temas poco importantes, como lo que hará el día de mañana, o que hará cuando llegué a casa.

\section{Comentarios y sugerencias}

\section{PREGUNTAS ADICIONALES}

¿Considera que las fases propuestas en este protocolo son suficientes para cumplir con el objetivo (Convenir un protocolo multidisciplinario para sistematizar la toma del testimonio haciendo más eficiente el proceso al igual que evitar la sobre-victimización en menores de edad)?

\section{¡GRACIAS POR SU PARTICIPACIÓN!}

